\title{
The Effects of South AfricA's Unexpected Monetary Policy SHOCKS IN THE COMMON Monetary Area
}

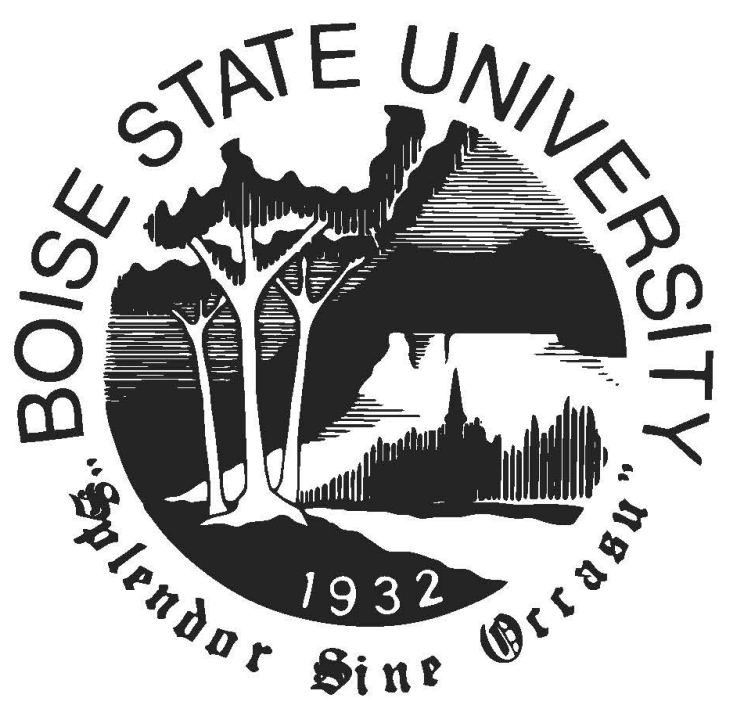

A thesis

submitted in partial fulfillment

of the requirements for the degree of

Master of Science in Economics

Boise State University 
(C) 2020

Bonang N. Seoela

ALL RIGHTS RESERVED 


\section{BOISE STATE UNIVERSITY GRADUATE COLLEGE \\ DEFENSE COMMITTEE AND FINAL READING APPROVALS}

of the thesis submitted by

Bonang N. Seoela

Thesis Title: The Effect of South Africa's Monetary Policy Shocks within the Common Monetary Area

Date of Final Oral Examination: March 11, 2020

The following individuals read and discussed the thesis submitted by student Bonang N. Seoela, and they evaluated the student's presentation and response to questions during the final oral examination. They found that the student passed the final oral examination.
Samia Islam, Ph.D.
Chair, Supervisory Committee
Michail Fragkias, Ph.D. Member, Supervisory Committee
Jingxian Hu, Ph.D. Member, Supervisory Committee
Leming Qu, Ph.D. Member, Supervisory Committee

The final reading approval of the thesis was granted by Samia Islam, Ph.D., Chair of the Supervisory Committee. The thesis was approved by the Graduate College. 


\section{DEDICATION}

I dedicate this work to the following people: 'Makamohelo Shiloh Seoela, 'Mabonang 'Makefuoe Seoela Moleleki, Khotso Moleleki, Mohau Seoela, Kefuoe Moleleki, 'Mathlonolofatso Seoela, and Thlonolofatso Seoela and my entire family and friends. Your love and support have been an immense source of motivation and encouragement. 


\section{ACKNOWLEDGEMENTS}

I want to take this opportunity to express my utmost gratitude and sincere regards to several people without whom this project could not have been possible. Firstly, I owe my highest debt of gratitude to Professor Samia Islam. I am tremendously thankful for her contributions to my work, as well as her confidence, patience and consistent assistance, which were essential throughout this research project. Secondly, I would like to thank Bahlakoana Mabetha for providing me with insightful feedback and comments. Thirdly, I am grateful to my thesis committee members for giving me valuable suggestions during the initial presentation of this paper. Finally, I am profoundly indebted to Professor Gina Greenway for encouraging me to continue my education in economics. 


\begin{abstract}
The Common Monetary Area (CMA) is a multilateral agreement that provides a framework for a fixed exchange rate regime between the South-African Rand and the currencies of Lesotho, Eswatini, and Namibia (LEN). The nature of the arrangement restrains the LEN countries from exercising independent discretionary monetary policy. As a result, they must rely on the South African authorities for policy formulation and implementation. Interest rates in the LEN countries cannot deviate too far from those in South Africa. Given this limited scope for monetary policy in the LEN countries, this study investigates how each member country adjusts to shocks to the South African monetary policy instrument. Specifically, this paper uses a structural vector autoregressive (SVAR) model to examine how economic output, inflation, narrow money supply, domestic credit, and lending rate spread in each member country react to shocks experienced in the South African repo rate using monthly data from the period 2000M2 to 2018M12. The main findings indicate that a positive shock to the South African repo rate tends to be followed by a decline in economic output and an appreciation in price levels at the 90 percent confidence interval for all CMA countries. Our results have also shown that there is an asymmetric response in money supply, domestic credit and lending rate spread between the LEN countries and South Africa, to a positive repo rate shock. These results suggest that policymakers in LEN countries must implement additional policy measures to circumvent the negative impact of South Africa's monetary policy on their financial sectors.
\end{abstract}

- JEL Classification: E41, E51, E52, E58, F42

- Keywords: CMA, Interest rate channel, Monetary policy transmission mechanism, Structural VAR 


\section{TABLE OF CONTENTS}

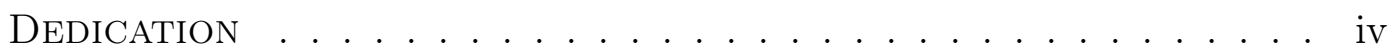

ACKNOWLEDGEMENTS . . . . . . . . . . . . . . . v v

ABSTRACT .................................

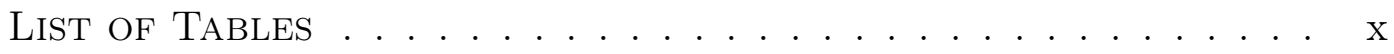

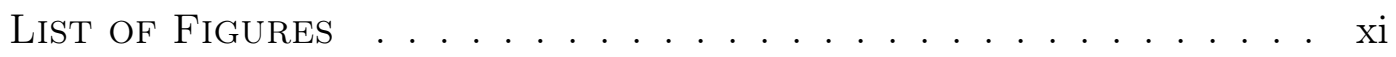

List of ABBREVIATIONS AND ACRONYMS . . . . . . . . . . . xii

1 INTRODUCTION 1

2 The Common Monetary Area 4

2.1 Historical Background . . . . . . . . . . . . . . . . 4

2.2 Institutional Arrangements . . . . . . . . . . . . . . 5

2.3 Monetary Policy Framework . . . . . . . . . . . . . . . . . . . . 6

2.2.1 South Africa . . . . . . . . . . . . . . . . . . . . . 9

2.2.2 Eswatini . . . . . . . . . . . . . . . . . 10

2.2.3 Lesotho . . . . . . . . . . . . . . . . . . . . . 10

2.2.4 Namibia . . . . . . . . . . . . . . . . . . . . . . 11

3 Literature Review

3.1 Theoretical Framework . . . . . . . . . . . . . . . . . . 13

3.2 Empirical literature . . . . . . . . . . . . . . . . 16

3.2.1 Developed Economies . . . . . . . . . . . . . . . . . 18

3.2.2 Emerging Market Economies . . . . . . . . . . . . . . . 19

3.2.3 Common Monetary Area . . . . . . . . . . . . . . . . . . . 21 
4.1 Data Description . . . . . . . . . . . . . . . . 25

4.2 Temporal Disaggregation . . . . . . . . . . . . . . . 25

4.2.1 The Chow-Lin Approach . . . . . . . . . . . . . . . 26

4.2.2 Estimating Monthly GDP . . . . . . . . . . . . . . 28

4.3 Unit Root Tests . . . . . . . . . . . . . . . . . . . . . . . . 29

4.4 Cointegration . . . . . . . . . . . . . . . . . 31

4.5 Model Specification . . . . . . . . . . . . . . . . . 31

4.5.1 Impulse Response Functions . . . . . . . . . . . . . . . 33

4.5.2 Forecast Error Variance Decomposition . . . . . . . . . . . . . 33

4.6 SVAR Identification: Short-run restrictions . . . . . . . . . . . . . 34

4.7 Diagnostic Tests . . . . . . . . . . . . . . . . . 37

5 Results And Empirical Analysis 38

5.1 Descriptive statistics . . . . . . . . . . . . . . . . . . 38

5.1.1 Correlation Analysis . . . . . . . . . . . . . . . . 39

5.2 Stationarity Tests . . . . . . . . . . . . . . . . . . 39

5.3 Cointegration Tests f. . . . . . . . . . . . . . . . . . 41

5.4 Optimal Lag Selection Criteria . . . . . . . . . . . . . . 41

5.5 Structural VAR Results . . . . . . . . . . . . . . . . . . . 42

5.5.1 Impulse Response Functions . . . . . . . . . . . . . . . . . . . 42

5.5.2 Forecast Error Variance Decomposition . . . . . . . . . . . . . 49

6 Robustness Analysis $\quad 51$

7 Discussion And Conclusion $\quad 53$

7.1 Policy Recommendations . . . . . . . . . . . . . . . . 54

7.2 Limitations and Further Research . . . . . . . . . . . . . . 54

REFERENCES

$\begin{array}{ll}\text { Appendix A } & 62\end{array}$ 
A.1 Definition of Variables . . . . . . . . . . . . . . . . 62

$\begin{array}{ll}\text { Appendix B } & 64\end{array}$

B.1 History of the Common Monetary Area . . . . . . . . . . . . . . . 64

B.2 Institutional Arrangement of the CMA . . . . . . . . . . . . 64

$\begin{array}{ll}\text { Appendix C } & 67\end{array}$

C.1 CMA Descriptive Statistics, 2000M1-2018M12 . . . . . . . . 67

C.2 Correlation Matrices . . . . . . . . . . . . . . . . 68

C.3 Unit Root Tests . . . . . . . . . . . . . . . . . . . . . . . 69

C.4 Johansen Cointegration Test . . . . . . . . . . . . . 71

C.5 VAR Lag Order Selection Criteria . . . . . . . . . . . . . . . 72

C.6 Variance Decomposition Results . . . . . . . . . . . . . . . . . 72

C.7 Robustness Checks . . . . . . . . . . . . . . . 74 


\section{List of Tables}

5.1 Summary statistics: Country-specific averages, 2000M2-2018M12 . . 38

5.2 Likelihood test of over-identifying restriction . . . . . . . . . . . 42

6.1 Joint residual heteroskedasticity and normality tests . . . . . . . . . 52

6.2 Lagrange-Multiplier test for serial autocorrelation . . . . . . . . . 52 


\section{List of Figures}

2.1 The Open-economy Policy Trilemma . . . . . . . . . . . . . . . 7

2.2 Foreign exchange market response to repo rate changes . . . . . . . 8

3.1 Monetary policy transmission mechanism in the CMA . . . . . . . 16

4.1 Graphical inspection of the GDP proxy . . . . . . . . . . . . . 28

4.2 Estimated monthly GDP, 2000M2 - 2018M12 . . . . . . . . . . 29

5.1 Graphical stationarity test at levels, 2000M2-2018M12 . . . . . . . 40

5.2 Economic output responses to a repo rate shock . . . . . . . . . . . 43

5.3 Inflation responses to a repo rate shock . . . . . . . . . . . . 44

5.4 Money supply responses to a repo rate shock . . . . . . . . . . . . 45

5.5 Domestic credit responses to a repo rate shock . . . . . . . . . . . 46

5.6 Lending rate spread responses to a repo rate shock . . . . . . . . . 47 


\section{List of Abbreviations and Acronyms}

BON Bank of Namibia. 11

CBE Central Bank of Eswatini. 10

CBL Central Bank of Lesotho. 11

CMA Common Monetary Area. 1

GDP Gross Domestic Product. 3

IRF Impulse Response Function. 3

IT Inflation Targeting. 1

LEN Lesotho, Eswatini, and Namibia. 1

LSL Lesotho Loti. 5, 64

MPTM Monetary Policy Transmission Mechanism. 2

NAD Namibian Dollar. 5

RMA Rand Monetary Area. 4

SARB South African Reserve Bank. 1

SVAR Structural Vector Auto Regression. 3

SZL Eswatini Lilangeni. 5, 64

ZAR South African Rand. 5, 64-66 


\section{INTRODUCTION}

The Common Monetary Area (CMA) is a multilateral agreement that provides a framework for a fixed exchange rate regime between the South African rand (ZAR) and the currencies of Lesotho, Eswatini ${ }^{1}$, and Namibia (LEN countries). The main objective of this currency union is to foster the sustained economic development and advancement of the less developed members (Wang et al., 2007). The Agreement gives member countries the power to issue their local currencies with the South-African bilateral agreements dictating the areas where the currencies are legal tenders. A crucial concern about the structure of the CMA is the absence of a joint central bank that is responsible for conducting monetary policy interventions and is accountable to all member countries. The CMA arrangement constrains the LEN countries from exercising independent discretionary monetary policy. As a result, South Africa's economic superiority over the LEN countries is exerted through its sole discretion over monetary policy decisions in the region. The South African Reserve Bank (SARB) is responsible for monetary policy formulation and implementation with its local economy as their primary target. The core assumption for this policy arrangement is that as long as the LEN currencies are fixed to the ZAR and the SARB pursues a domestic policy of low and stable inflation, policy effects will be transmitted from the South African economy to the rest of the LEN countries without delay (Seleteng, 2016).

Following SARB's adoption of an inflation rate targeting (IT) regime in 2000, there have been growing debates among researchers on the efficacy of this policy instrument. Several studies in South Africa suggest that SARB's inflationtargeting framework is ineffective in restraining inflationary pressures within the target range (Ikhide and Uanguta, 2010; Bonga-Bonga and Kabundi, 2015; Seleteng, 2016; Ajilore and Ikhide, 2013). For example, during the period from 2014

\footnotetext{
${ }^{1}$ Before 2018, Eswatini was known as Swaziland.
} 
to 2016, the SARB entered a contractionary phase when forecasts indicated that inflation was expected to rise. These contractionary monetary policy episodes are found to have negatively affected economic growth in South Africa, especially in manufacturing production (Bonga-Bonga and Kabundi, 2015). There is a limited number of research studies that extend this analysis to the LEN countries. Empirically, it is still not understood how South Africa's monetary policy decisions affect the LEN economies and the channels through which these effects are transmitted.

The effect of monetary policy transmission on output, prices, investment, and other key economic indicators has been subject to ongoing debates in monetary economics. It has been widely observed that Monetary Policy Transmission Mechanism (MPTM) functions through various channels; namely, interest rate channel, exchange rate channel, bank credit channel and equity price channel (Ireland, 2005; Mishkin, 1995). Friedman (1968) stressed that the linkage between policy instruments and their targets is essential to our understanding of what monetary policy can accomplish. Without a clear idea of what is within reach of a central bank in terms of controlling economic activity, it is not possible to make sensible choices regarding monetary policy (Chatterjee, 2002).

Given the limited scope for monetary policy adjustment by the LEN countries, it is crucial to understand how policy-induced changes are transmitted from South Africa to the LEN countries for the following reasons. Firstly, a clear and functional understanding of the monetary policy transmission mechanism may help authorities and policymakers to precisely ascertain the relative effectiveness of the channels to achieve policy targets. Secondly, since the financial sector in the LEN countries is highly integrated with their South-African counterpart, adequate information about the mechanism may enable appropriate weights and emphasis to be placed on monetary policy targets and goals during monetary policy design and implementation. Finally, in the case where these channels do not optimally function for a member country, an adjustment mechanism such as liquidity management may be implemented to restore the economy to equilibrium, thus correcting 
domestic liquidity imbalances.

This study addresses the gap in the literature on the CMA and its impact on the LEN countries by comparatively evaluating the transmission of South Africa's monetary policy shocks in the Common Monetary Area. This study empirically attempts to answer the questions: How do policy-induced changes affect macroeconomic indicators in the CMA? How effectively does each member country respond to these changes? We use a structural vector autoregressive (SVAR) methodology and impulse response functions (IRFs) to address these questions. In particular, this paper assesses how economic output, inflation, narrow money supply, domestic credit, lending rate spread across the CMA countries react to shocks in the South African repo rate. Following the works of Ikhide and Uanguta (2010) and Seleteng (2016), this study similarly identifies the South African repo rate (henceforth referred to as, repo rate) as the relevant monetary policy instrument of the CMA. Unlike previous studies in the CMA, this study uses monthly data from February 2000 to December 2018 to better reflect the short-run dynamics of monetary policy during the IT period. Monthly GDP data is estimated from quarterly observations using the Chow-Lin (1971) regressions approach. The U.S. federal reserve funds rate is included in the estimated model to control for changes to domestic monetary policy due to external shocks following studies such as Kim and Roubini (2000) and Aslanidi (2007).

The rest of the research paper is structured as follows: Chapter two presents an overview of the CMA, the structure of the arrangement and unique features of monetary policy for each member country. Chapter three provides a review of the theoretical and empirical studies of MPTM in developed and emerging market economies. Chapter four describes the data used in this study. This chapter also presents the theoretical background of an SVAR model, empirical model specification, and discusses time-series tests adopted. Chapter five provides the results of this study. Chapter six provides the results of robustness tests. Chapter seven discusses the implications of our findings and future research questions. 


\section{The Common Monetary Area}

\subsection{HistoricAl BaCKGRound}

The origins of the CMA can be traced back to the establishment of the SARB in 1921, which created a de facto currency union between Eswatini, Lesotho, Namibia and South Africa (Collings, 1978; Wang et al., 2007). The South African currency (initially the pound) was established as an exclusive regional medium of exchange and legal tender in Botswana, Eswatini, Lesotho, and South Africa ${ }^{1}$. Internal movement of capital within the region was not subject to any restrictions, and all external transactions were executed through South African banks under South African exchange control regulations. Following the end of World War II, the ruling Nationalist Party in South Africa introduced major reforms that culminated in isolation from Britain, and the introduction of a new currency, the South African rand, in 1961. After Botswana, Eswatini, and Lesotho gained independence, negotiations with South Africa began that resulted in the official establishment of a currency union through the signing of the Rand Monetary Area (RMA) in 1974. However, Botswana withdrew ${ }^{2}$ from the agreement a year later due to concerns that membership in the RMA constituted loss of independent monetary policy power (Metzger, 2004).

In 1986, the RMA was updated to create the current structure of the Common Monetary Area, which gave Lesotho and Eswatini the right to issue their national currencies. Although Namibia was not formally a member of the CMA, it has always been integrated into the CMA through South Africa (Metzger, 2004). Namibia remained under South-Africa's military occupation after it was invaded during World War I and maintained this status until it became independent in

\footnotetext{
${ }^{1}$ During this period, Botswana, Eswatini, Lesotho were still under the British Colonial rule.

${ }^{2}$ However, Botswana is often called a de facto member of the current CMA because its floating currency is pegged to a currency basket, with the South African rand accounting for an estimated $60 \%-70 \%$ of the weight (Wang et al., 2007).
} 
1990. Subsequently, it joined the CMA in 1992, which marked the formation of the current multilateral CMA arrangement. For more details about the history of the region, refer to Appendix B.1, extracted from Wang et al. (2007).

\subsection{Institutional Arrangements}

Tjirongo (1995) and Wang et al. (2007) have comprehensively summarised the structure of the CMA as follows ${ }^{3}$ : Each of the four members has an independent central bank, which is responsible for implementing policies and issuing national currencies. The currencies of Lesotho (LSL), Eswatini (SZL), and Namibia (NAD) have been pegged one to one with the South African Rand (ZAR). The ZAR is the only currency that circulates as legal tender throughout the entire CMA region while currencies of the rest of the members are restricted within their respective borders. Individual LEN currencies and the ZAR are perfect substitutes, with no conversion costs. In order to support the fixed exchange rate regime, LEN countries are required to back their currency issues with foreign exchange reserves. The reserves are kept in a common pool managed by SARB, and they can be made available upon any member's request. There are no restrictions to intra-CMA funds transfers (capital or current transactions). However, all CMA members apply a common exchange control system that is determined by the South African authorities. The LEN currencies receive annual payments from South Africa to compensate them for foregone seigniorage ${ }^{4}$. The amount of ZAR circulating in the LEN countries is not directly measured; it is estimated. Van den Heever (2010) estimated that the ZAR accounted for approximately 76 percent of the total money in circulation in the LEN countries during the period between 2006 to 2007. However, the LEN countries do not include the ZAR when reporting the total amount of money circulating within their countries.

The CMA countries, together with Botswana, belong to the Southern African Customs Union (SADC), a regional trading block. Consequently, there is very high

\footnotetext{
${ }^{3}$ Refer to appendix B.2 for further details.

${ }^{4}$ Seigniorage refers to the profit made by the government of a country from issuing currency.
} 
capital and goods mobility among member countries in the CMA. This mobility gives the LEN countries access to the South African financial markets. There is also consultation among members that enhances policy implementation through yearly meetings. However, there has been growing concerns in recent years in the LEN countries about South Africa's dominance in designing monetary policy for the whole region (Metzger, 2004; Alweendo, 2000), concerns which, in part, motivated this study.

\subsection{Monetary Policy Framework}

According to standard macroeconomics theory, monetary policy can be broadly described as measures taken by the central bank to influence short-term interest rates and the supply of money and credit to achieve a set of objectives (Mishkin, 2014). The short term interest rate refers mainly to the bank rate (the rate at which the central bank lends to commercial banks), the repo rate (the rate at which the central bank provides overnight liquidity for commercial banks) and the inter-bank rate (the rate at which commercial banks borrow from each other). The goal of central banks is to maintain a monetary policy which is neither excessive (which may lead to an increase in inflation) nor deficient (which may lead to an increase in unemployment).

Many countries have implemented a wide range of monetary policy strategies that have successfully reduced inflation while maintaining relatively low levels of unemployment (N'Diaye and Laxton, 2002). Inflation rate targeting (IT) is a monetary policy strategy that has received growing recognition in both developed and emerging market economies. According to a popular paper by Bernanke and Mishkin (1997), IT policy requires the monetary authority to announce the numerical inflation target. If inflation falls outside this target, the central bank should use short-term interest rates to restore inflation within the target range. Another common monetary policy strategy that uses a nominal anchor to promote price stability is exchange-rate targeting. Mishkin (2014) has pointed out that the modern approach to exchange-rate targeting involves fixing the value of the domestic 
currency to a large, low-inflation anchor country. This strategy is particularly useful for small market economies because the anchor country directly contributes to the goal of price stability.

In the pursuit for price stability, central banks are confronted by a problem known as the policy trilemma (Mishkin, 2014). This hypothesis states that a country can simultaneously choose any two, but not all of the following three policy goals: free capital mobility, fixed exchange rate, and sovereign monetary policy (Mishkin, 2014). Figure 2.1 illustrates that a country can only choose one out of the three options. For example, a country that chooses option one will have capital mobility and independent monetary policy, e.g. the United States and South Africa. In the second option, a country gives up monetary policy in exchange for free movement of capital and price stability, e.g. the LEN countries. The third option is chosen by a country that pursues independent monetary policy and has a fixed exchange rate, e.g. China.

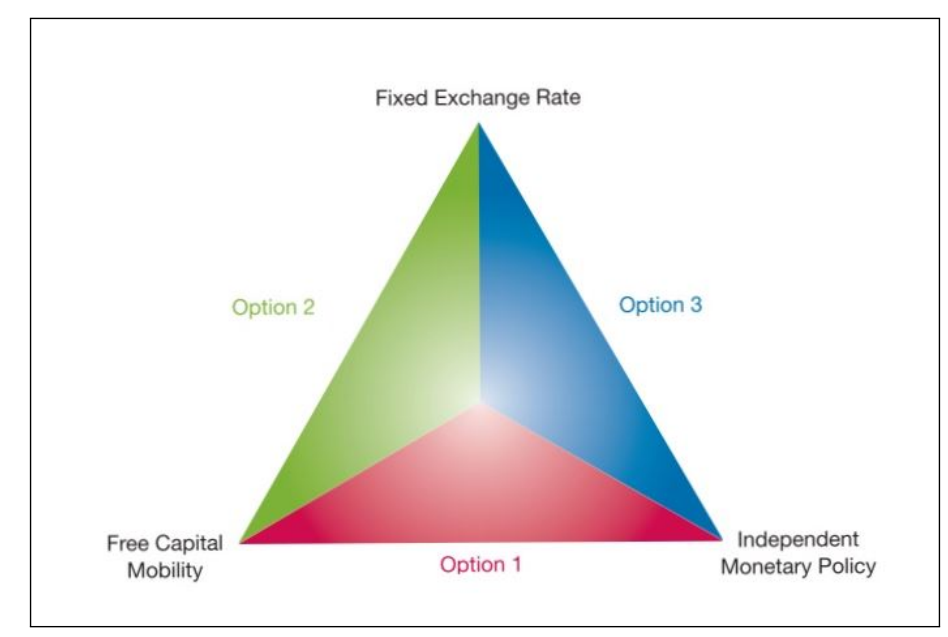

Figure 2.1: The Open-economy Policy Trilemma Source: Mishkin (2014, p. 439)

The institutional arrangement of the CMA discussed in the previous section suggests that the LEN countries have surrendered their independent monetary policy to South Africa. The LEN countries must, therefore, set their interest rates within a close range to those in South Africa. Failure to follow interest rate movements in South Africa may lead to distortion to the fixed exchange rate (Alweendo, 2000). For example, if South Africa pursued a contractionary 
monetary policy and increased the repo rate, this will result to lower expected inflation in South Africa thus causing the ZAR to appreciate relative to the LEN currencies $^{5}$. This can be represented by an increase in the demand for ZAR assets, as shown in figure 2.2. When the repo rate increases, the relative expected returns on South African assets increases and the demand curve shifts from $D_{1}$ to $D_{2}$. The equilibrium exchange rate between the ZAR and the LEN currencies increases from 1 to $E_{1}$. In response, the LEN countries could sell the ZAR and buy their domestic currency in order to keep their currencies from depreciating. However, this policy action would lead to a continuing decline in their (LEN) international reserves, until the LEN countries are forced to devalue their currencies against the ZAR. Therefore the LEN countries can no longer control their monetary policy because movements in their interest rates are determined by movements in South Africa's repo rate.

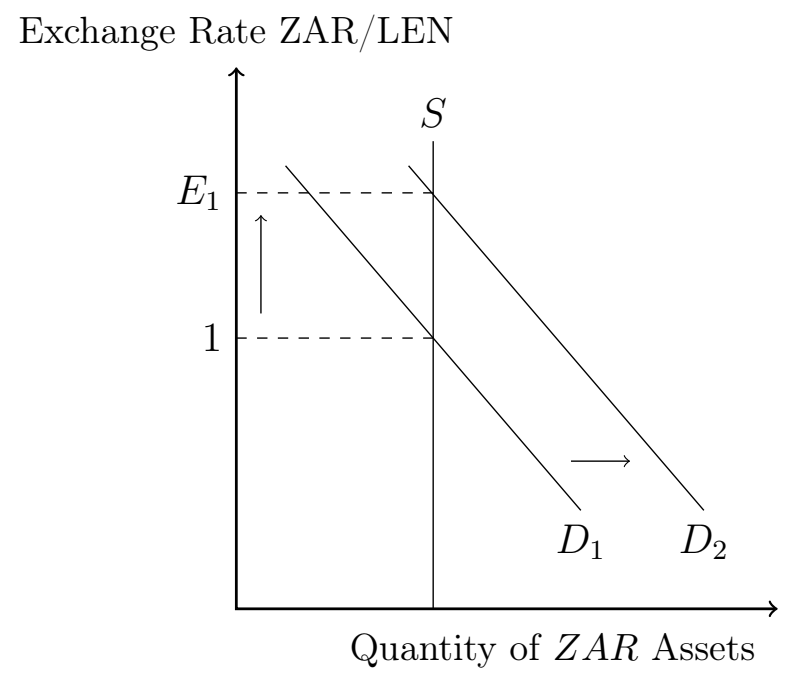

Figure 2.2: Foreign exchange market response to repo rate changes

Policymakers in the LEN countries have undertaken various policy measures in attempts to bolster their local economies. However, these efforts to re-focus domestic monetary policy to domestic developments in the LEN have been unsuccessful (Ikhide and Uanguta, 2010). The scope for implementation of monetary policy in the CMA and the recent developments are reviewed below.

\footnotetext{
${ }^{5}$ An important assumption here is that nothing else was changed other than the repo rate.
} 


\subsubsection{South Africa}

The CMA arrangement provides the SARB with a wider range of monetary policy options relative to the rest of the members. Consequently, monetary policy instruments implemented in South Africa have implications for the rest of the CMA. Before 2000, the SARB operated under an eclectic approach to monetary policy, where growth in money supply and credit extension were used as intermediate guidelines for short term interest rates. However, this policy was not transparent and sometimes questionable actions were taken that were costly to the domestic economic growth (Aron and Muellbauer, 2007). The inflation targeting approach was adopted to enhance policy transparency, accountability and predictability. Under South African IT framework, the appropriate measure of inflation was identified as CPIX (CPI less mortgage interest rates) which is specifically maintained within a target range of 3 to 6 percent $^{6}$. The repo rate remains the main operational tool for maintaining price stability. The adoption of the IT framework marked the SARB's shift to a floating exchange rate regime to ensure the competitiveness of South-Africa's exports. However, the IT approach in South Africa has been experiencing a decline in efficiency over time, as evidenced by the failure of high interest rates to keep inflation within the target range (Meyer, De Jongh, and Van Wyngaard, 2018). Other related studies suggest that SARB's inflation target range is very low for conducive economic growth in the LEN countries. For instance, Mosikari and Eita (2018) estimates that the optimal level of inflation for Eswatini is 12 percent, while Seleteng (2005) estimated 10 percent for Lesotho. This suggests that the SARB's policies which lower inflation to the target band may have a negative impact on the LEN economies. In recent years following the 2008 global financial crisis, the SARB added a complementary mandate to oversee and maintain financial stability, which to some extent may influence the effect of monetary policy not only in South Africa but throughout the rest of the CMA.

\footnotetext{
${ }^{6}$ According to the South African Constitution, the inflation target is determined by the Minister of Finance in consultation with the SARB. The choice of policy instruments used to achieve this target is solely in the discretion of the bank (Coco and Viegi, 2019).
} 


\subsubsection{Eswatini}

Before 1995, the Central bank of Eswatini (CBE) had adopted an interest rate policy that was independent of conditions in South-Africa. This was done in part as an effort to encourage investment by providing cheaper capital. After South Africa became a democratic state in 1994, the attractiveness of Eswatini as an investment hub for South African firms shifted (Wang et al., 2007). The decline in investment, coupled with the effects of prolonged drought, was followed by a period of low GDP growth. In response, the CBE introduced new policy measures that aim to reduce the interest rate differential between Eswatini and South Africa. In this policy framework, the CBE uses the central bank rate as a major policy instrument to counter inflationary pressures and curb capital flight (Central Bank of Swaziland, 2017). This rate can be set at par with that in South Africa or at slightly different levels depending on the domestic economic situation. In addition, CBE also uses other policy instruments such as liquidity and reserve requirements to promote price and financial stability. However, the effectiveness of these instruments is shrouded by excess liquidity in the domestic banking system and the lack of highly liquid financial products (Ikhide and Uanguta, 2010). As a result, domestic commercial banks tend to manage their funds through high yield financial markets in South Africa. Therefore, the CBE cannot effectively use bank rates to influence domestic money market rates. The central bank rate effectively serves as an economic indicator for the level of interest rate rather a benchmark for lending.

\subsubsection{Lesotho}

According to Alweendo (2000), the Central Bank of Lesotho's (CBL) approach to monetary policy before 1998 was primarily through direct and indirect manipulation of interest rates. The deposit rate and lending rates in Lesotho were set slightly lower relative to South Africa. Commercial banks were also subject to Minimum Local Assets Ratio (MLAR), which was intended to attract domestic investment for development projects. After 1998 this policy was gradually phased 
out, and commercial banks were then allowed to determine their lending and savings deposit rate. The MLAR was replaced by the Liquid Assets Ratio (LAR). This is because commercial banks are risk-averse and prefer to keep their deposits with the central bank rather than providing credit to the private sector. Introduction of treasury bill auctions has been a recent attempt to curb excess liquidity within the banking sector in Lesotho (Ikhide and Uanguta, 2010). This advancement is expected to offer competitive investments and hence prevent excessive capital outflows ${ }^{7}$. In addition, the CBL also introduced a new bank rate which is intended to provide institutional lenders with a reference when determining their rates. The results of these policy changes have not been effective at narrowing the interest rate gap between Lesotho and South Africa. Lending rates in Lesotho are still higher than those in South Africa, while deposit rates in South Africa are higher than in Lesotho (Ikhide and Uanguta, 2010; The Economist, 2015).

\section{$\underline{\text { 2.3.4 Namibia }}$}

As the last member to join the CMA, the Bank of Namibia (BON) has had to undertake considerable efforts to catch up with its fellow members in terms of policy implementation (Tjirongo, 1995). BON was established in 1990, following Namibia's independence from South Africa. Namibia's economic dependence on South Africa meant that moving forward after independence, additional measures had to be taken to ensure stability and confidence in the economic and financial systems (Kalenga, 2001). The BON views the reserve requirement as a crucial policy instrument for influencing economic activity in Namibia (Alweendo, 2000). The central bank rate is also used to control domestic inflation, similar to Eswatini and Lesotho, but this only acts as a reference point for interest rates in Namibia. The BON has developed other policy innovations such as the call account facility which enables commercial banks to place funds with the BON at an interest rate below the Bank rate. This facility enables commercial banks to overdraw their

\footnotetext{
${ }^{7}$ If left unchecked, capital outflows put pressure on the net international reserves, which in turn may threaten the exchange rate peg (Central Bank of Lesotho, 2019).
} 
account held with the BON. There is, however, limited effectiveness of these policy instruments to influence the economy. For instance, open market operations have a limited effect on the overall economy since a large share of treasuries/stocks are owned by institutional investors (Bank of Namibia, 2008).

The above discussion on the structure and monetary policy framework in the CMA explains why a fixed exchange rate requires the LEN countries to give up independent control of monetary policy. South Africa is, therefore, responsible for monetary policy formulation and implementation in the region. In order to understand the impact of South Africa's monetary policy stance in the LEN countries, insights from the experiences of other countries engaged in similar regional agreements can be beneficial. 


\section{Literature REVIEW}

\subsection{Theoretical Framework}

The nature of monetary policy transmission mechanisms is a concern for countries in the establishment of a currency union. Understanding the transmission mechanism enables the selection of policy instruments that result in symmetric outcomes for all member countries. Monetary policy transmission mechanism defines the reaction of real variables (such as GDP and employment) to policy-induced changes in the nominal money stock or short-term nominal interest rate (Ireland, 2005). There are mainly four channels of monetary policy transmission recognized by economists, namely; interest rate channel, exchange rate channel, bank credit channel and equity price channel. However, there are different views on the relevance and significance of these channels, hence, there is less agreement about the way monetary policy exerts its influence on the real sector of the economy ${ }^{1}$. Given the complexity of the monetary policy transmission mechanism, a useful way to understand the efficacy of monetary policy is to isolate the central bank's policy actions and the transmission mechanisms through which those actions work their effect (Loayza and Schmidt-Hebbel, 2002).

This research paper focuses specifically on the interest rate channel of the monetary policy transmission mechanism. The interest rate channel is the traditional mechanism and often considered the main channel of monetary policy transmission (Taylor, 1995; Loayza and Schmidt-Hebber, 2002). Hicks (1937) introduced the model that explains the linkage between money and the interest rate to aggregate income. The predictive power of the model relies on a set of core assumptions. Ndubuisi (2015) suggests that the following assumptions are crucial in understanding how the interest rate channel functions:

\footnotetext{
${ }^{1}$ See Twinoburyo and Odhiambo (2018) for a summary of the recent literature.
} 
(i) The central bank directly and perfectly controls money supply, outside money ${ }^{2}$, and/or the short-term rates: This enables the central bank to make credible policies that can impact the policy instruments and the effects transmitted to the economy.

(ii) There are no perfect substitutes to the central bank's monetary policy instruments: Since central banks frequently affect the markets through open market operations, other agents must lack the ability to offset them to cause desired changes on the monetary base.

(iii) Nominal rigidities: Nominal variables are assumed sticky due to imperfect competition in price and wage setting. This implies that firms are subject to some constraints on the frequency of adjustment to changes in prices of goods and services they sell. Sticky prices ensure that the nominal and real interest rates do not contemporaneously rise with an increase in the money supply.

(iv) Expectation hypothesis of the interest rate term structure: This assumption establishes a link between the interest rate and different returns on securities. Market participants are assumed to have expectations about this and hence link the short term rates to the long term rates.

In the study of the effects of money on economic activity, two approaches have been developed: reduced models and structural models. On the one hand, Keynesian economists use structural models to examine how money affects economic activity within a model which explains the behaviours of consumers and firms. If the model is appropriately specified, then each transmission channel can be evaluated separately and hence the effect of institutional changes (financial innovations, regulations) can be estimated. In the traditional Keynesian view, the transmission of a contractionary monetary policy to the real economy is explained as follows (Mishkin, 1995):

$$
M \downarrow \Longrightarrow i \uparrow \Longrightarrow I \downarrow \Longrightarrow Y \downarrow
$$

\footnotetext{
${ }^{2}$ This axiom is hardly met in reality due to the actions and inactions of banks and non-banks.
} 
A contractionary monetary policy $(M \downarrow)$ will cause an increase in real interest rates $(i \uparrow)$. This will cause an increase in the cost of capital, and thus a decline in investment $(I \downarrow)^{3}$. Ultimately, this process will end with a decline in aggregate demand and output $(Y \downarrow)$.

On the other hand, monetarists use reduced models to analyze the effect of money on economic activities by checking the relationship between output $(Y)$ and money $(M)$ in an economy where it is like a "black box" and inside of it cannot be seen (Bernanke and Gertler, 1995; Mishkin, 2014).

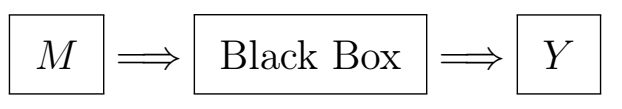

If a tight monetary policy is applied, there will be an increase in the short-term nominal interest rates, which in turn increases long-term nominal interest rates. This is due to investor attempts to arbitrage away differences in the risk-adjusted expected returns on debt instruments of various maturities. This phenomenon can be explained by the expectation hypothesis of the interest rate term structure (Gedikli, 2017). As nominal prices and wages (both assumed rigid) gradually self-adjust, movements in nominal interest rates are transferred into movements in real interest rates. Consequently, firms will prefer to decrease their investment expenditure due to the increasing cost of borrowing. Likewise, households also reduce their spending on durable goods due to rising real cost of borrowing. A combination of these changes will result in the reduction of aggregate output and domestic inflation.

\footnotetext{
${ }^{3}$ Households' decisions about housing, and durable consumer expenditures are also included as investment decisions.
} 


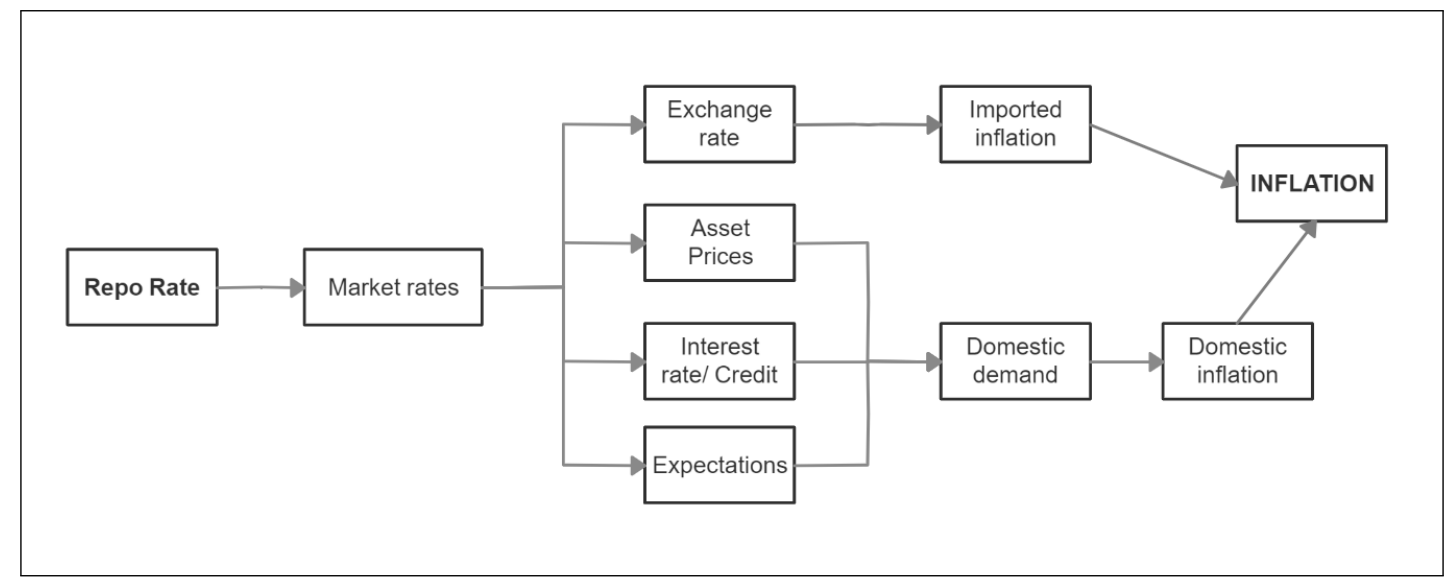

Figure 3.1: Monetary policy transmission mechanism in the CMA Source: Bank of Namibia, and Central Bank of Eswatini

Figure 3.1 shows a schematic illustration of the monetary policy transmission mechanism in the CMA. Due to their relatively small size, the LEN countries import a large amount of their inflation from South Africa since it is their largest trading partner (Bank of Namibia, 2008; Wang et al., 2007). For example, if the SARB suspects there is excess liquidity in the South African markets, it increases the repo rate to create shortages. Commercial banks in the CMA respond by increasing their lending rates to reflect the increased cost of borrowing. This will decrease the demand for money and ultimately, the total demand. Consequently, the price levels will decrease as total spending declines.

\subsection{EMPIRICAL LITERATURE}

Following Sims (1980), it has become common for economists to estimate the effects of monetary policy on the real economy using vector autoregressive (VAR) models (Aslanidi, 2007). This approach treats all the variables in the system as endogenous, thus, solving the problem of bi-directional effects the variables can have on each other. Also, the VAR enables the study of the impact of monetary policy on the real economy without imposing structural restrictions on the model of the economy (Kim and Roubini, 2000). However, one of the major criticisms against VAR models is the ordering of variables. In order to recover monetary policy shocks from the VAR residuals, the Cheloskey decomposition is used. The 
Cheloskey method orders the variables in a particular sequence such that only variables placed higher in the sequence have a contemporaneous effect on the variables placed lower in the ordering. Zha (1997) argued that VAR might not be appropriate to identify the relationship between policy instruments and money market variables. This is because, in reality, monetary instruments and financial variables can have a contemporaneous effect on variables placed higher in the sequence.

Structural vector autoregressive (SVAR) models have been alternatively used to identify structural shocks of monetary policy. This approach relaxes the assumptions of the VAR models. SVAR models allow for contemporaneous relations between monetary policy variables and financial variables. The SVAR derives its name from the fact that it is a vector autoregressive model generated by an economic model ("structure"). The SVAR approach emerged from seminal works of Blanchard and Watson (1984), Cooley and Leroy (1985), Bernanke (1986), and Sims (1986). These authors used theoretically motivated restrictions to estimate structural parameters and identify structural shocks. For example, Blanchard and Watson (1984) used economic theory to impose short-run restrictions in order to investigate the influence of shocks on the business cycle. An SVAR model is useful in estimating monetary policy shocks because they allow one to impose theoretically motivated restrictions on the relationship between variables. This study, thus, uses the SVAR methodology.

This section reviews the empirical studies on macroeconomic effects of monetary policy shocks. Given the lack of a unified view on how monetary policy transmission mechanism functions, several research techniques have been adopted to estimate the effect of monetary policy on price levels, output, domestic credit, wages, money money and exchange rate using different monetary policy instruments (Ishioro, 2013). It is important for the reader to note that there is a very limited number of studies that extend this body of work to the CMA region, especially in the LEN countries. As a result, closely related literature focusing on 
other regions is also reviewed to improve comparison and provide context to the current study.

\subsubsection{Developed Economies}

Some empirical studies that focus on developed countries that have contributed to the debate on the effect of monetary policy on the real economy include Leeper, Sims, and Zha (1996) who used an SVAR framework that allows for the contemporaneous impact of monetary policy on target variables. The study investigated the transmission mechanism of monetary policy in the United States using monthly data from 1959 to 1996 . The study asserts that monetary policy shocks do not cause large changes in output, but they have a stronger effect on prices. The authors argue, therefore, that the observed relationship between high interest rates and low output is not caused by contractionary policy but by high inflationary pressure instead.

Peersman and Smets (2001) applied an identified VAR model to analyse the macroeconomic effects of unexpected monetary policy shocks in the Euro area using data from 1980 to 1998 . The results showed that an unexpected positive shock to the interest rate tends to be followed by a temporary decline in output and a real appreciation of the exchange rate. Prices were found to be sticky as they raised with a lag several quarters later. This result is known as the "price puzzle". This is a case where price levels rise in response to monetary tightening, rather than fall (Kim and Roubini, 2000). Smets and Wouters (2003) used DSGE models combined with Bayesian methods of inference and found evidence of the interest rate channel of monetary policy transmission in the Euro area.

Arestis and Sawyer (2003) argues that a "new" approach to monetary policy emerged that identifies interest rate policy rather than the stock of money. As a result, the paper focuses on the transmission of monetary policy through the interest rate channel in the Eurozone, United Kingdom, and the United States. The results of the study argue that a sequence of effects from the reserve bank discount rate to the final target of the rate of inflation is long and uncertain. 
Also, the relationship between the exchange rate and interest rate expressed in the interest rate parity approach have constraints on the degree to which the domestic interest rate can be set to address the domestic levels of aggregate demand and inflation. The results suggest that there is a relatively weak effect of interest rate changes on inflation. Based on these findings, the authors conclude that monetary policy can have long-run effects on real magnitudes. This, however, does not comfortably fit with the theoretical basis of the new monetary policy approach.

In Japan, Iwata and Wu (2006) investigated the impact of exogenous monetary shocks when nominal rates are at zero. They used a nonlinear structural VAR model to examine the impact the zero bound constraint on the effectiveness of counter-cyclical monetary policies. The findings were that when interest rates are near zero, the output effect of exogenous shocks to monetary policy is cut by up to 50 percent if the central bank continues to target the interest rate. The conditional impulse response functions were used to isolate the effect of monetary policy shocks operating through the interest rate channel when other possible channels of monetary transmission are present. Their results confirmed that the interest channel is the most important mechanism of monetary policy transmission.

The reviewed literature from industrialised countries suggests that researchers have not yet reached a consensus about the impact of monetary policy on macroeconomic variables. An important lesson drawn from these studies is that appropriate control for exogenous shocks is useful for avoiding the price puzzle. Earlier research such as Peersman and Smets (2001) and Arestis and Sawyer (2003) have encountered this puzzling dynamic response. Kim and Roubini (2000) suggested that incorporating foreign variables in the model may help to resolve this puzzle.

\subsubsection{Emerging Market Economies}

Following the debates on monetary policy transmission mechanism in the U.S. and other developed countries, similar studies have been conducted in developing countries. Economic conditions of developing countries in the sub-Saharan Africa 
region are comparable as most countries in this region are low income with weak institutions (Twinoburyo and Odhiambo, 2018). Notable studies in the region include Cheng (2006) who applied both recursive and non-recursive SVAR model to monthly data in Kenya for the period 1997 to 2005. The findings showed that a contractionary monetary policy leads to an initial increase in the price level, followed by a statistically significant decline for a period of about two years following the shock. The response to a contractionary monetary policy was an initial rise in output but eventually falls. However, the decline is not statistically significant. Shocks to the interest rate were found to explain a much larger fraction of inflation than output. The authors concluded that there is evidence of exchange rate pass-through to inflation given that positive shocks to interest rates lead initially to an exchange rate depreciation, but eventually appreciates for about two years.

Mirdala (2009) estimated an SVAR model for the countries from the Visegrád Group $^{4}$ to analyze the sources of movements in real output for the period from 1999 to 2008. The findings revealed that a positive monetary policy shock has a high impact on the real output variability, which implies that the real output is sensitive to changes in monetary policy. The estimated impact of nominal shocks on real output was mixed across countries. For some countries, nominal shocks caused a decrease in output while for some countries, positive nominal shocks caused an increase in output.

Buigut (2009) estimated a three-variable recursive VAR for three East African Community $(\mathrm{EAC})^{5}$ countries using data from the period 1984 to 2006. The paper explored the importance of the interest channel in the region. The main finding is that the interest rate transmission mechanism is weak in all three countries. A shock to the interest rate has no statistically significant effect on either inflation or real output. However, Davoodi, Dixit, and Pinter (2013) argued that these

\footnotetext{
${ }^{4}$ The Visegrád group consists of four Central European states: Cyprus, Malta, the Slovak Republic and Slovenia.

${ }^{5}$ The author focused on Kenya, Tanzania, and Uganda.
} 
findings are biased by several factors: (i) The study uses a sample that includes too few observations for empirical analyses, resulting in few degrees of freedom; (ii) it includes periods of substantial changes in monetary policy implementation, financial deepening, and other structural shifts in each economy which may have contributed to large uncertainty surrounding the effectiveness of monetary policy. Davoodi, Dixit, and Pinter (2013) proposed that using a Bayesian VAR model could resolve these issues because it provides an effective way of dealing with of over-parameterization. In contrast, their results found that an expansionary monetary increases prices significantly in Kenya and Uganda and output in Burundi, Kenya, and Rwanda.

Evidence from the selected studies in the sub-Saharan Africa region has motivated this study as follows: Monthly data from February 2000 to December 2018 is used to ensure that there are sufficient observations for econometric estimation. In the case of GDP (which is only available on a quarterly frequency), this study uses the Chow-Lin (1971) approach to estimate monthly frequency. This study will also incorporate robustness tests to ensure that structural breaks in the data have been sufficiently controlled.

\subsubsection{Common Monetary Area}

Only two studies that compare the effect of South-Africa's monetary policy conduct on the economies of the CMA countries were found in the literature. Ikhide and Uanguta (2010) and Seleteng (2016) examined the impact of SARB's monetary policy on the LEN economies using a VAR framework. Seleteng (2016) used annual data from 1980 to 2012 while Ikhide and Uanguta (2010) used monthly data $^{6}$. These studies focused on how changes in the SARB's monetary policy instrument (repo rate) affects money supply, credit and prices in the CMA and thus evaluating the ability of the LEN economies to undertake independent monetary policy under the prevalent structure. Both studies found statistically significant results that lending rates and price levels were instantaneously sensitive to changes

\footnotetext{
${ }^{6}$ Ikhide and Uanguta (2010) did not disclose the period under study.
} 
in the repo rate. However, Ikhide and Uanguta (2010) also found that money supply is instantaneously responsive to the repo rate, while Seleteng (2016) did not find any significant relationship. These significant differences may be attributed to several factors such as the difference in the period under study, specification of the model and structural breaks. Ikhide and Uanguta (2010) confirmed that the repo rate is a relevant policy instrument in the LEN economies. Both studies concluded that the LEN countries are not capable of independent monetary policy given the nature of their agreement with South-Africa.

There are also country-focused studies that have attempted to disentangle the transmission of monetary policy in the CMA. For example, Gumata, Kabundi, and Ndou (2013) investigated the presence of different MPTM channels in South Africa using a Large Bayesian VAR model with quarterly data from the period 1990Q1 to 2012Q2. Their results showed that credit, interest rate, asset prices, exchange rate, and expectations channels are all potent in the South African economy, but differ in magnitudes. The study concluded that the interest rate channel was the most important transmitter of monetary policy shocks. Bonga-Bonga (2010) examined the responses of the short and long-term interest rates to monetary, demand and supply shocks in South-Africa using data from 1986 to 2007. The empirical analysis conducted in this study followed an SVAR methodology with long-run restrictions. The author found that the effects of monetary policy shocks caused the short and long-term interest rates to move in the same direction. However, the short-run and long-run interest rates move in different directions in the presence of positive supply shocks.

Mkhonta (2018) used a panel fixed effects approach to ascertain the impact of the discount rate differential between the Eswatini and Namibian rates and the South Africa rates. Quarterly data from the period 2010Q1 to 2015Q4 was used. The results suggest that the interest rate differential is statistically insignificant in affecting investments in both countries. However, when an indicator of financial development is included, the results improve. Therefore, the authors argue that 
financial developments are crucial in Eswatini and Namibia in order to enhance the efficacy of monetary policy.

In Namibia, Sheefeni and Ocran (2012) used an SVAR methodology with longrun restrictions to investigate how interest rate channel of monetary policy transmission affects prices and output in Namibia. The authors used quarterly data for the period from 1993 to 2009. The results revealed that short term interest rates have an effect on domestic output and price levels. The authors concluded that the presence of the interest rate channel suggests that the Bank of Namibia might be able to influence long-term rates through open market operations. Dlamini and Skosana (2017) similarly used an SVAR approach to provide evidence of the linkage between monetary policy and selected macroeconomic variables in Eswatini. The study used monthly data from 1990 to 2015. The findings showed the existence of a weak monetary policy transmission in the interest rate channel, credit channel, and asset price channel.

The reviewed literature from the CMA shows that most studies examined the monetary policy transmission mechanism in the CMA using VAR or SVAR models. These studies included data from the period before and after the inflation targeting regime was adopted. The selected studies reveal mixed results regarding the effectiveness of monetary policy in the CMA. Some studies found a causal relationship from monetary policy instruments to macroeconomic variables (Ikhide and Uanguta, 2010; Seleteng, 2016; Sheefeni and Ocran, 2012) while others found that monetary policy is ineffective (Mkhonta, 2018; Dlamini and Skosana, 2017). Our study follows the recommendations of Blanchard and Watson (1984), amongst others, to identify monetary policy shocks in the CMA using an SVAR approach. Although the results may not change drastically, this paper will explore where structural identification will help to address the inconsistencies in the literature. Unlike previous studies in the CMA, data used in this study focuses on the period after the inflation targeting regime was adopted, following Davoodi, Dixit, and Pinter (2013). This approach will ensure that the estimated results are consistent 
since the monetary policy transmission mechanism is sensitive to structural shifts. Most of the reviewed studies did not incorporate any controls for external changes that may influence the implementation of monetary poly in the CMA. The U.S. federal funds rate will be included in the estimated model to control for exogenous shocks to the repo rate, as recommended by Kim and Roubini (2000). 


\section{Methodology}

\subsection{Data Description}

This study uses monthly time series data for the period 2000M2 to 2018M12, for four member countries of the CMA: Eswatini, Lesotho, Namibia and South Africa (227 observations for each country). Macroeconomic data for individual countries were sourced from reports from the South African Reserve Bank, Central Bank of Lesotho, Bank of Namibia, and Central Bank of Eswatini. Missing data was complemented with reports from the International Monetary Fund's International Financial Statistics. Following Ikhide and Uanguta (2010), Seleteng (2016), and Famoroti and Tipoy (2019), data on the following variables were gathered; economic output $(l g d p)$, inflation ${ }^{1}(l c p i)$, narrow money $\operatorname{supply}^{2}(l m 1)$, domestic credit $(l d m)$, and lending rate spread (lrs). All of these variables, except economic output, were obtained at a monthly frequency. A statistical approach described in section 4.1.1 was adopted to interpolate monthly GDP from observed quarterly data. A description of the variables and abbreviations is provided in appendix 7. Consistent with past studies, (Bernanke, 1986: Ikhide and Uanguta, 2010; Davoodi, Dixit, and Pinter, 2013) for example, the following variables have been log-transformed: money supply, inflation, domestic credit, economic output.

\subsection{Temporal Disaggregation}

One of the challenges that researchers have to address is the lack of macroeconomic data (such as GDP, Inflation rates) at desired frequencies (quarterly, monthly). Several temporal disaggregation methods have been developed in recent years to address this problem. Temporal disaggregation is a process of estimating a high-frequency time series data using low-frequency data (Sax and Steiner, 2013).

\footnotetext{
${ }^{1}$ Indexed such that $\mathrm{CPI}_{2010 M 06}=100$.

${ }^{2}$ For the LEN countries, M1 does not include the estimated amount of ZAR circulating their respective countries.
} 
These methods can generally be classified into two categories; a) models based on an indicator series, e.g. Chow-Lin (1971) and Litterman (1983), and b) models developed without an indicator, e.g. Denton (1971). These techniques are particularly useful in this analysis because in estimating an SVAR model, all variables must have the same frequency.

\subsubsection{The Chow-Lin Approach}

The temporal disaggregation procedure adopted in this paper was developed by Chow and Lin (1971). It is commonly referred to as the best linear unbiased estimator (BLUE) because it uses a regression approach that relates the unknown frequency series to a set of known high-frequency series.

Let us suppose, without loss of generality, that we have annual values of $n$ years of a given time series $y_{a}$, the goal is to disaggregate $y_{a}$ into a quarterly series $\hat{y}_{q}$ with $4 n$ observations. The Chow-Lin approach to this problem is based on $x_{q}$, some observed quarterly indicator related to $y_{a}$. The relationship between the disaggregated series and the indicator is,

$$
\hat{Y}_{q}=X_{q} \beta+\varepsilon_{q}
$$

where $\hat{Y}_{q}$ is a $(4 n \times 1)$ vector of the estimated quarterly series, $X_{q}$ is the vector $(n \times 1)$ of observed quarterly series, $\beta$ is the vector of unknown parameters and is estimated using the Generalised Least Square (GLS) method, $\varepsilon$ is vector of stochastic disturbances with mean, $E(\varepsilon)=0$ and covariance $E\left(\varepsilon \varepsilon^{\prime}\right)=\sigma^{2} I=V_{q}$, $\sigma^{2}$ is a constant. The Chow-Lin can be adopted to our case in the following three steps:

\section{Step 1: Finding an Aggregation Matrix}

Since $\hat{Y}_{q}$ is a high frequency matrix of the unobserved series, the Chow-Lin approach transforms model (4.1) into a low frequency matrix of the observed series $Y_{a}$. This is achieved by pre-multiplying equation (4.1) by the aggregation matrix $C=c^{\prime} \otimes I_{n}$ such that $Y_{a}=\mathrm{C} \hat{Y}_{q}$, where $c^{\prime}=[1,1,1,1]$ and $\otimes$ denotes the kronecker product. The result of the aggregated model is, 


$$
Y_{a}=X_{a} \beta+\varepsilon_{a}
$$

where $X_{a}=C X_{q}, \varepsilon_{a}=C \varepsilon_{q}$ is the vector of aggregated disturbances with mean $E\left(\varepsilon_{a}\right)=C E\left(\varepsilon_{q}\right)=0$ and covariance $E\left(\varepsilon_{a} \varepsilon_{a}^{\prime}\right)=\sigma^{2} C I C^{\prime}=V_{a} . \quad \beta$ describes the parameters that characterize the relationship between $Y_{a}$ and $X_{a}$.

\section{Step 2: Finding the Chow-Lin disaggregation equation}

The next step is to establish the equation to disaggregate annual data to quarterly estimates. The optimal coefficient is determined by applying the GLS estimation method to the quarterly regression, thus

$$
\hat{\beta}_{G L S}=\left[X_{a}^{\prime}\left(C V_{q} C^{\prime}\right)^{-1} X_{a}\right]^{-1} X_{a}^{\prime}\left(C V_{q} C^{\prime}\right)^{-1} Y_{a}
$$

In order to find the Chow-Lin equation that disaggregates annual data to quarterly data, we follow from equation (4.2) where $\varepsilon_{a}=C \varepsilon_{q}$. We can re-write $\varepsilon_{q}$ as the subject of the formula and expand the function further as shown below,

$$
\begin{aligned}
& \varepsilon_{q}=V_{q} C^{\prime}\left(C V_{q} C^{\prime}\right)^{-1} \varepsilon_{a} \\
& \varepsilon_{q}=V_{q} C^{\prime}\left(C V_{q} C^{\prime}\right)^{-1}\left(Y_{a}-X_{a} \hat{\beta}_{G L S}\right)
\end{aligned}
$$

Equations (4.3) and (4.4) can be substituted into (4.1) to give the Chow-Lin equation that disaggregates annual data to quarterly estimates as shown below,

$$
\hat{Y}_{q}=X_{q} \hat{\beta}_{G L S}+V_{q} C^{\prime}\left(C V_{q} C^{\prime}\right)^{-1}\left(Y_{a}-X_{a} \hat{\beta}_{G L S}\right)
$$

\section{Step 3: Estimating the Covariance matrix under Chow-Lin Assumptions}

A major drawback of the Chow-Lin approach is that the covariance matrix $V_{q}$ is unknown. Chow-Lin (1971) proposed two assumptions under which $V_{q}$ could be better estimated, which are

i. the disturbances are not serially correlated, each with variance $\sigma^{2}$, then

$$
V_{q}=\sigma^{2} I
$$

ii. the quarterly disturbances $\varepsilon_{q}$, follow a simple autoregressive structure of first order, $\operatorname{AR}(1)$ as,

$$
\varepsilon_{t}=\rho \varepsilon_{t-1}+\mu_{t} \quad|\rho|<1 \forall t
$$

where $u_{t}$ is the white noise process; $\mu \sim i . i . d\left(0, \sigma_{\mu}^{2}\right), E\left(\mu_{t}\right)=0$ and $E\left(\mu_{t}^{2}\right)=\sigma^{2}$. Based on these assumptions, the variance-covariance matrix $V_{q}$ takes the form, 


$$
V_{q}=\frac{\sigma^{2}}{1-\rho^{2}}\left[\begin{array}{ccccc}
1 & \rho & \rho^{2} & \cdots & \rho^{4 n-1} \\
\rho & 1 & \rho & \cdots & \rho^{4 n-2} \\
\rho^{2} & \rho & 1 & \cdots & \rho^{4 n-3} \\
\vdots & \vdots & \vdots & \ddots & \vdots \\
\rho^{4 n-1} & \rho^{4 n-2} & \cdots & \cdots & 1
\end{array}\right]
$$

To estimate the autoregressive parameter $\rho$, Chow-Lin (1971) suggested a polynomial that needs to be solved ${ }^{3}$. If a sufficient length of quarterly data is available, then one may estimate $\rho$ from the OLS residuals of equation (4.1).

In this study, where the objective is to generate monthly GDP estimates from quarterly aggregates, if the monthly residuals follow an autoregressive parameter, then the first order auto-correlation of the quarterly residuals forms a polynomial expression in the autoregressive coefficient of the monthly residuals (Karan, 2013). Therefore, a process similar to the GLS can be constructed to obtain results implied by equations (4.4) and (4.6).

\subsubsection{Estimating Monthly GDP}

The data used in this estimation procedure is from the period from February 2000 to December 2018. The exports of goods and services were identified as a suitable indicator for economic growth. A visual inspection shown in figure 4.1 shows that exports generally exhibit co-movements with GDP.
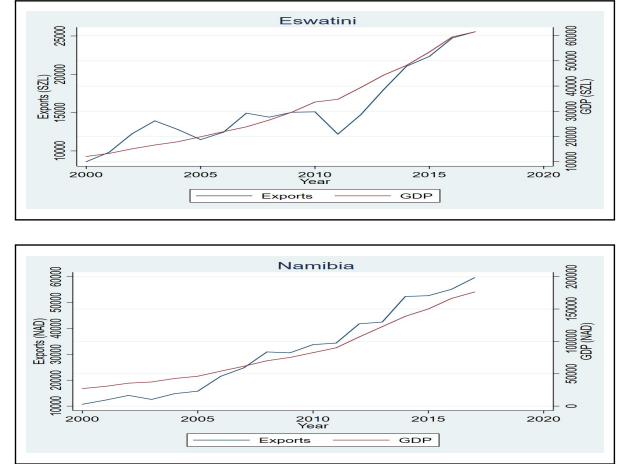

Figure 4.1: Graphical inspection of the GDP proxy Source: Author's own contribution
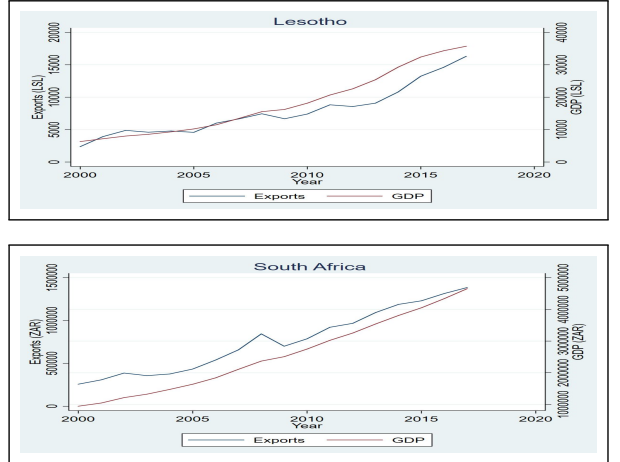

\footnotetext{
${ }^{3}$ The following polynomial needs to be solved, $\hat{\rho}_{a}=\frac{\rho+1)\left(\rho^{2}+1\right)^{2}}{2\left(\rho^{2}+\rho+2\right)}$ where $\hat{\rho}_{a}$ is the estimated first-order autocorrelation coefficient from the OLS residuals of the annual-data regression (4.2)
} 
The results of the monthly economic output series estimated using Chow-Lin (1971) are shown in figure 4.2. The results show that the estimated monthly GDP exhibits similar movements to the quarterly data for all countries. The results also show larger volatility for South Africa starting from the period around 2008. These patterns could be explained by changes observed in figure 4.1 during the same period. Since South Africa and Namibia are the largest exporters in the CMA, the effects of the external shocks will be greater compared to Lesotho and Eswatini.

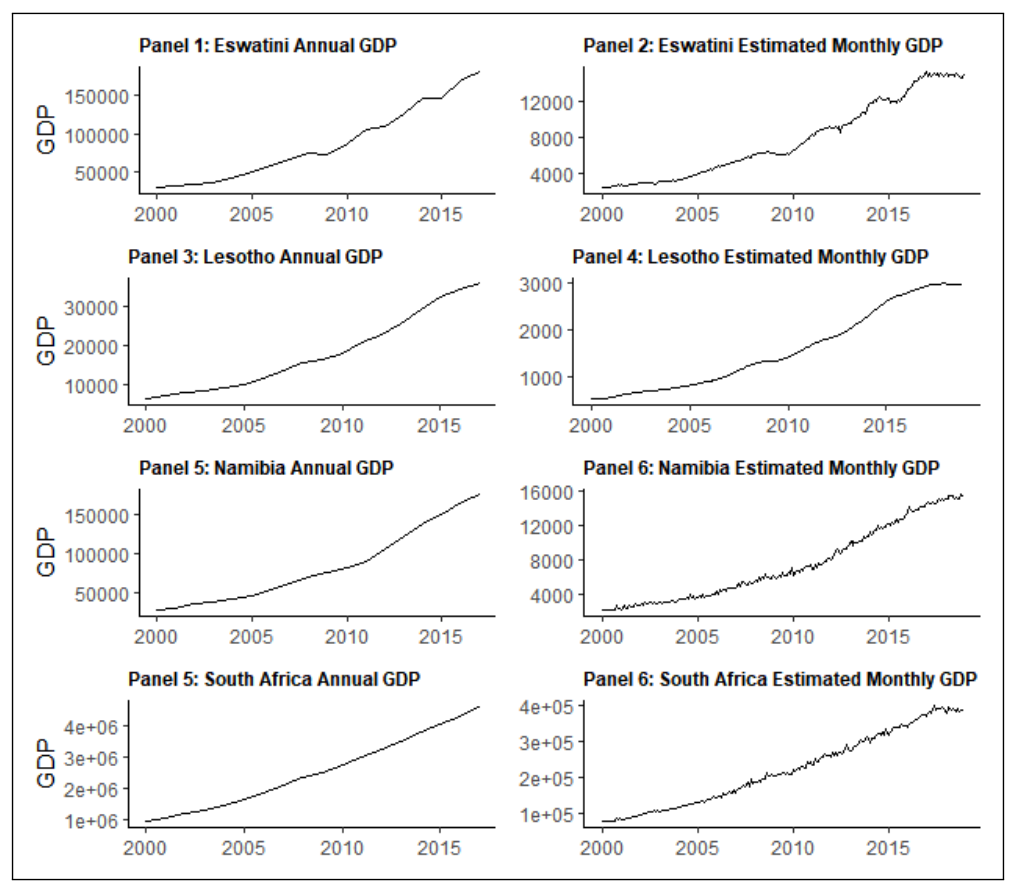

Figure 4.2: Estimated monthly GDP, 2000M2 - 2018M12

\subsection{Unit Root Tests}

The Classical regression model assumptions require both the independent and dependent variables to be stationary, and that the errors must have a zero mean and finite variance. However, many economics and financial time series data display trending behaviour or non-stationarity in the mean (Zivot and Wang, 2005). A stochastic data generating process $y_{t}$ is said to be stationary if it has timeinvariant mean and variance. That is, the time-series generated by a stationary stochastic process fluctuates around a constant mean and does not trend. Non- 
stationarity results in spurious regressions that are characterized by high $R^{2}$, and $\mathrm{t}$ and F-statistics that appear to be significant but the results do not have any economic interpretation (Lütkepohl, 2005). Unit root tests have hence been developed to guide decisions whether trending data should be differenced first or regressed on deterministic functions of time to render the data stationary. The Augmented Dickey-Fuller (ADF) test is the most commonly used method for testing unit root. The null hypothesis under the ADF test is that $Y_{t}$ is $I(1)$ against the alternative that it is $I(0)$. The ADF test is based on estimating the following test regression,

$$
\Delta Y_{t}=\mu+\phi Y_{t-1}+\sum_{i=1}^{p} \psi_{i} \Delta Y_{t-i}+\varepsilon_{t}
$$

where $p$ is the lagged difference terms, its value is set so that the error $\varepsilon_{t}$ is serially uncorrelated. The error term is also assumed to be homoskedastic. The null hypothesis of $\mathrm{ADF}$ is $\phi=0$ (non-stationarity) against the alternative hypothesis of $\phi<0$ (stationarity).

However, relative caution is required when dealing with time-series data. The ADF test is often found to be biased towards accepting the null hypothesis $\left(H_{0}\right)$ and thus require further affirmation. This is because; a) it has very low power against $I(0)$ alternatives that are very close to being $I(1)$, b) its power diminishes as deterministic terms are added to the test of regression (Sheefeni and Ocran, 2012). The Kwiatkowski, Phillips, Schmidt and Shin (KPSS) test is therefore used to complement the ADF test because of its efficiency and superior power. The KPSS can distinguish highly persistent stationary processes from non-stationary processes very well. In the KPSS test, the null hypothesis is stationary, and the alternative hypothesis is non-stationary. KPSS test is based on estimating the following test regression,

$$
Y_{t}=X_{t}+\varepsilon_{t} \quad \text { and } X_{t}=X_{t-1}+\mu_{t}
$$

where $\varepsilon_{t}$ is the error term. The KPSS statistic is based on the residuals from the OLS regression of $Y_{t}$ on the exogenous variables $X_{t}$. Thus the hypothesis is 
tested for $u_{t}$.

\subsection{Cointegration}

Shrestha and Bhatta (2017) propose that non stationary variables that are integrated of the same order should be tested for cointegration. Two variables are said to be cointegrated if they are each unit root processes, but their linear combination is stationary. In other words, cointegration between two variables exists if they have a long-run relationship. This study follows the Johansen (1988) and Johansen and Juselius (1990) approach to cointegration. Johansen cointegration test is based on the relationship between the rank of a matrix and its characteristic roots. The generalised model with $n$ variable vectors can be written as

$$
Y_{t}=A_{1} Y_{t-1}+\varepsilon_{t}
$$

subtracting $Y_{t-1}$ from both sides, we get

$$
\begin{aligned}
\Delta Y_{t} & =A_{1} Y_{t-1}-Y_{t-1}+\varepsilon_{t} \\
& =\left(A_{1}-I\right) Y_{t-1}+\varepsilon_{t} \\
& =\Pi Y_{t-1}+\varepsilon_{t}
\end{aligned}
$$

where $Y_{t-1}$ and $\varepsilon_{t}$ are $(n \times 1)$ vectors, $\Pi$ is a $(n \times n)$ matrix. If rank of $\Pi=k$ then the series is stationary and if rank of $\Pi<k$, also known as reduced rank, then there exists cointegration. The trace test tests the null hypothesis of $k$ cointegrating vectors against the alternative hypothesis of $n$.

\subsection{Model Specification}

This paper adopts an SVAR approach to trace the impact of shocks on the repo rate on selected macroeconomic variables in Eswatini, Lesotho and Namibia. The strength of this model lies in the use of forecast error variance decomposition to quantify the average contribution of a given structural shock to the variability of the data over time. Structural VAR model is a multivariate, linear representation of a vector of observable variables lagged on itself. Let $n$ be the number of endogenous variables in the model, following (Bernanke, 1986; Kim and Roubini, 2000; Aslanidi, 2007), the structure of each economy in the CMA can be described in a 
reduced form as

$$
\begin{aligned}
& Y_{t}=\sum_{i=1}^{p} A_{i} Y_{t-i}+B X_{t}+\varepsilon_{t} \\
& Y_{t}=A_{1} Y_{t-1}+\cdots+A_{p} Y_{t-p}+B X_{t}+\varepsilon_{t}
\end{aligned}
$$

where $Y_{t}$ is an $(n \times 1)$ vector of endogenous variables observed at time $t$. $X_{t}$ is a vector of exogenous variables. $A_{i}$ is an $(n \times n)$ vector of coefficient estimates, $\varepsilon_{t}$ is an $(n \times 1)$ vector of of serially uncorrelated reduced form disturbances, and $p$ is the optimal lag length of each variable. The variance-covariance matrix is, $E\left(\varepsilon_{t} \varepsilon_{t}^{\prime}\right)=\varphi$.

Equation 4.9 can be reparameterized into its structural form as

$$
\begin{aligned}
\Gamma_{0} Y_{t} & =\sum_{i=1}^{p} \Gamma_{i} Y_{t-i}+\Pi X_{t}+\mu_{t} \\
& =\Gamma_{1} Y_{t-1}+\cdots+\Gamma_{p} Y_{t-p}+\Pi X_{t}+\mu_{t}
\end{aligned}
$$

where $\Gamma_{0}$ is the contemporaneous coefficients matrix with the diagonal elements normalized to equal one but the off-diagonal elements may be arbitrary. $\Gamma_{i}$ represents the matrices of the parameters of the economic variables, and $\mu_{t}$ represents the structure of the economic shock, with variance and covariance matrices denoted as, $E\left(\mu_{t} \mu_{t}^{\prime}\right)=\vartheta$.

Therefore, the link between the reduced (Eq. 4.11) and structural (Eq. 4.12) forms is,

$$
A_{i}=\Gamma_{0}^{-1} \Gamma_{i}, \quad B=\Gamma_{0}^{-1} \Pi, \quad \text { and } \mu_{t}=\Gamma_{0} \varepsilon_{t}
$$

Likewise, the variance-covariance matrix relationship between reduced and structural forms can be written as

$$
\varphi=\Gamma_{0} \vartheta\left(\Gamma_{0}^{-1}\right)
$$

The reduced form can be estimated using OLS, and point estimates of the parameters $\left(A_{i}\right)$ and variance-covariance matrix $(\varphi)$ can be found. However, identifying restrictions have to be imposed to recover the structural form parameters.

The estimates for $\vartheta$ and the parameters in the structural form representation can be obtained only through the estimates of $\varphi$. The matrix $\vartheta$ has $n(n+1)$ parameters to be estimated, while $\varphi$ contains only $n(n+1) / 2$. Thus, at least 
$n(n-1) / 2$ restrictions must be imposed on the contemporaneous matrix $\Gamma_{0}$ to recover the structural form parameters.

\subsubsection{Impulse Response Functions}

Following the identification, the structural innovations $\left(\mu_{t}\right)$ can be recovered from the residuals $\varepsilon_{t}$. The impulse response functions (IRFs) and forecast error variance decomposition (FEVDs) can also be estimated. The impulse response functions are used to trace out the effect of structural innovations on observed variables. That is, IRFs describe the evolution of the variable of interest along a specified time horizon after a shock in a given moment. The SVAR can be rewritten in a vector moving average form in terms of structural innovations as,

$$
Y_{t}=\varepsilon_{t}+\sum_{i=0}^{\infty} \phi_{i} \mu_{t-1}
$$

where $\phi_{i}$ are used to generate the effects of structural innovations on time paths of data sequences. A plot function will depict the response of variables $Y_{t+j}$ for all $j$ after a shock at time $t$. The IRFs can alternatively be presented $a^{4}$,

$$
\operatorname{IRF}_{i j}(l)=\frac{\partial Y_{j, t+l}}{\partial \mu_{i t}}=\phi_{i} \quad l=1,2, \ldots
$$

\subsubsection{Forecast Error Variance Decomposition}

Forecast error variance decomposition is a way to quantify how important each shock is in explaining the variation in each of the variables in the system. It is equal to the fraction of the forecast error variance of each variable due to each shock at each horizon. FEVD are usually carried out based on the moving average representation shown in equation 4.14 with the h-step forecast error for the process written as,

$$
Y_{t+h}-Y_{t}(h)=\sum_{i=0}^{h-1} \phi_{i} \mu_{t+h-1}
$$

with $Y_{t}(h)$ being the optimal h-step forecast at period t for $X_{t+h}$. The corresponding shares of individual innovations to this variance is given $b y^{2}$,

$$
\gamma_{i j}(h)=\frac{\sum_{l=0}^{h} I R F_{i j}^{2}(l)}{\sum_{i=1}^{n} \sum_{l=0}^{h} I R F_{i j}^{2}(l)} \quad i, j=1, \ldots, n
$$

\footnotetext{
${ }^{4}$ see section 2.3, Lütkepohl (2005)
} 
where $\sum_{i=1}^{K} \gamma_{i j}(h)=1$ for a given variable $j$.

\subsection{SVAR IDENTIFICATION: Short-run restrictions}

This section describes the set-up of an SVAR model for the economies of Eswatini, Lesotho, Namibia and South-Africa. A six-variable SVAR model was estimated independently for each CMA country following Kim and Roubini (2000) and Aslanidi (2007). The estimated SVAR model for country $i$, in time period $t$ has the following endogenous variables,

$$
Y_{i t}=\left[\operatorname{sarr}_{t}, l r s_{i t}, l d c_{i t}, \operatorname{lm} 1_{i t}, l c p i_{i t}, \lg d p_{i t}\right]^{\prime}
$$

The U.S. Federal Funds rate $\left(f f r_{t}\right)$ is included exogenously in models as a control for foreign monetary policy shocks in setting domestic monetary policy (Kim and Roubini, 2000; Aslanidi, 2007). The repo-rate ( $\left.\operatorname{sarr}_{i t}\right)$ is used as a measure of domestic monetary policy stance in the CMA. The real GDP $\left(l g d p_{i t}\right)$ and inflation $\left(l c p i_{i t}\right)$ represent the economic activity in each country and help to characterize the market in the economy. The short term interest rates are represented by the lending rate spread $\left(l r s_{i t}\right)$. This enables an investigation into the interaction of monetary policy and the interest rate channel. Finally, domestic credit extension $\left(l d c_{i t}\right)$ and narrow money supply $\left(l m 1_{i t}\right)$ are important macroeconomic indicators that capture the level of economic activity. These variables are included to identify their dynamic effects on the real sector of the economy.

The focus of this paper is centred on the analysis of the resulting IRFs and FEVDs which estimate the responses of given variables to innovations in another variable in the system, ceteris paribus. As discussed earlier in the previous section, the estimation of the SVAR requires an identification scheme where a set of theoretically valid restrictions are imposed on the elements of the contemporaneous matrix $\Gamma_{0}$. However, Famoroti and Tipoy (2019) and others argue that specifying the model restrictions is a daunting task. This is because it is not clear which aspects of the model arises due to the assumptions imposed on the model and which arise from the data. Aslanidi (2007) argue that the method of imposing restrictions is not different from other specification methods, although the results 
are likely to be sensitive to model specification and imposed restrictions. They point that this approach makes the results more transparent because it can be supported by economic theory.

The econometric identification of monetary policy shocks is crucial to the model specification. Consequently, this study specifically follows the identification scheme adopted by Kim and Roubini (2000) and Aslanidi (2007). However, the model is modified to take into account the context of monetary policy conduct in the CMA. The structural shocks are identified from their reduced form $\left(\varepsilon_{t}\right)$ by imposing restrictions on the contemporaneous matrix $\Gamma_{0}$ based on equation 4.13:

$$
\left[\begin{array}{l}
\mu_{l g d p} \\
\mu_{l c p i} \\
\mu_{l m 1} \\
\mu_{l d c} \\
\mu_{l r s} \\
\mu_{\text {sarr }}
\end{array}\right]=\left[\begin{array}{cccccc}
1 & 0 & 0 & 0 & 0 & 0 \\
\Gamma_{21} & 1 & 0 & 0 & 0 & 0 \\
\Gamma_{31} & \Gamma_{32} & 1 & 0 & 0 & 0 \\
\Gamma_{41} & \Gamma_{42} & \Gamma_{43} & 1 & \Gamma_{45} & \Gamma_{46} \\
0 & \Gamma_{52} & 0 & \Gamma_{54} & 1 & \Gamma_{56} \\
0 & \Gamma_{62} & 0 & 0 & 0 & 1
\end{array}\right]\left[\begin{array}{c}
\varepsilon_{l g d p} \\
\varepsilon_{l c p i} \\
\varepsilon_{l m 1} \\
\varepsilon_{l d c} \\
\varepsilon_{l r s} \\
\varepsilon_{s a r r}
\end{array}\right]
$$

The structural disturbance in the model are represented by the $\mu_{i t}$ matrix where; $\mu_{l g d p} \rightarrow$ domestic output shocks, $\mu_{l c p i} \rightarrow$ domestic inflation shocks, $\mu_{l m 1} \rightarrow$ money supply shocks, $\mu_{l d c} \rightarrow$ domestic credit shocks, $\mu_{l r s} \rightarrow$ lending rate spread shocks, and $\mu_{\text {sarr }} \rightarrow$ repo rate shocks. The residuals from reduced form equation $\left(\varepsilon_{i t}\right)$ show the unexpected changes in each variable given the information available.

The non-zero coefficients indicate that a variable $i$ affects contemporaneously variable $j$. The restrictions imposed on the $\Gamma_{0}$ matrix are based, firstly, on the timing of information. A zero restriction is imposed based on the fact that some variables are available to monetary authorities after a lag (e.g. GDP, inflation). Secondly, behavioural restrictions are imposed on variables that respond slowly to movements in financial and policy variables. The following restrictions are imposed on the contemporaneous matrix based on theoretical economic expectations;

1. The first and second equations represent the goods market. Economic output responds to price and financial signals (interest rate and credit) with a 
lag. This restriction reflects the assumption of nominal rigidities. Producers do not instantaneously alter output and prices in response to innovations in financial variables and monetary policy within a short time horizon. The price equation is assumed to be contemporaneously affected by changes in output (Aslanidi, 2007).

2. The money supply equation is assumed to be the reaction function of the monetary authority, which sets the level of money after observing the current values of output and the price levels (Kim and Roubini, 2000).

3. Domestic credit is assumed to contemporaneously respond to domestic output, price levels, money supply and interest rates shocks. This is because the real activity and domestic interest rates give households expectations of future economic activity (Kim and Roubini, 2000). Similarly, the lending rate spread is assumed to contemporaneously change with all variables except GDP and money supply due to information lag. Borrowers will quickly respond to the changes in the real cost of borrowing.

4. Finally, the repo is the main monetary policy instrument in the CMA; hence we assume that it is the SARB's monetary reaction function. Given the inflation-targeting framework, the repo rate contemporaneously responds only to changes in inflation, but not to any other variables. This means that the reserve bank sets the repo rate only after observing the current level of inflation (Ikhide and Uanguta, 2010; Seleteng, 2016).

In the case of a six-variable SVAR model, a just-identified model requires at least 15 restrictions. This study imposed 18 restrictions on the contemporaneous matrix. That is, the estimated model is over-identified. The over-identifying restrictions can be validated/rejected by computing a likelihood ratio (LR) test that compares the log-likelihood of the structural form and the log-likelihood of the reduced form(Lütkepohl and Krätzig, 2004). Given the restrictions on $\Gamma_{0}$, the structural system of contemporaneous variables can be expressed as 


$$
\begin{aligned}
l g d p_{t} & =\mu_{l g d p} \\
\Gamma_{21} l g d p_{t}+l c p i_{t} & =\mu_{l c p i} \\
\Gamma_{31} l g d p_{t}+\Gamma_{32} l c p i_{t}+l m 1_{t} & =\mu_{l m 1} \\
\Gamma_{41} l g d p_{t}+\Gamma_{42} l c p i_{t}+\Gamma_{43} l m 1_{t}+l d c_{t} & =\mu_{l d c} \\
\Gamma_{52} l c p i_{t}+\Gamma_{54} l d c_{t}+l r s_{t}+\Gamma_{56} \operatorname{sarr}_{t} & =\mu_{l r s} \\
\Gamma_{62} l c p i_{t}+\operatorname{sarr}_{t} & =\mu_{\text {sarr }}
\end{aligned}
$$

\subsection{Diagnostic Tests}

Diagnostic tests are used to check the stochastic properties of the model, such as residual autocorrelation, heteroskedasticity, normality and model stability. Since the identification assumptions are not independently testable, a sensitivity analysis will be performed to determine how the structural analysis based on the IRFs is influenced by the selected lag structure. This sensitivity analysis is based on estimating the SVAR for different lag structures. If the IRFs change considerably for different lags of the variables, then we conclude that the assumed lag structure heavily influences the structural inference (Zivot, 2000). 


\section{Results And Empirical ANALYsis}

\subsection{Descriptive STATistics}

Appendix 7.1 presents the descriptive statistics of all variables in Eswatini, Lesotho, Namibia, and South Africa. The results show that the lending rate spread and the repo rate are highly volatile, as evidenced by the high standard deviations. The skewness measures whether the distribution of the data is symmetrical or asymmetrical. Money supply, inflation, domestic credit and economic output are negatively skewed while the rest are positively skewed. This indicates that all variables are not normally distributed. The significance of the Jarque-Bera statistic also confirms the non-normality of all variables.

Table 5.1: Summary statistics: Country-specific averages, 2000M22018M12

\begin{tabular}{ccccccc}
\hline \hline Country & LM1 & LCPI & LDC & LRS & LGDP & SARR \\
\hline Eswatini & 3.30 & 1.97 & 3.16 & 6.68 & 3.39 & - \\
Lesotho & 3.43 & 1.96 & 3.08 & 8.96 & 3.13 & - \\
Namibia & 4.19 & 1.96 & 4.47 & 5.10 & 3.79 & - \\
South Africa & 5.85 & 1.98 & 6.23 & 3.86 & 5.29 & 8.03 \\
\hline Source: & South African Reserve Bank, Central Bank of \\
Lesotho, Bank of Namibia, and Central Bank of Eswatini, \\
and the International Monetary Fund.
\end{tabular}

Table 5.1 compares the average values of the variables across the CMA. The cross-country comparison reveals the economic and financial weight of the South African economy within the CMA. South Africa has the highest economic output at 95 percent of the entire region, while Lesotho accounts for only 0.65 percent. Also, South Africa has the highest domestic credit extension and money supply, followed by Namibia. As noted earlier, these differences are in part ascribed to commercial banks in the LNS countries, transferring their excess liquid funds to financial markets in South Africa. Lending spread rate is widest in Lesotho at 8.96 percent and narrowest in South Africa at 3.86 percent. However, there is evidence 
of convergence in price levels ${ }^{1}$ in the CMA. The average inflation rates lie closely together between 91.2 and 95.5. This convergence in prices reveals the nature of the CMA arrangement, which enables tariff-free trade and no costs for currency conversion within the region.

\subsubsection{Correlation Analysis}

The results of the correlation analysis for each CMA member country is presented in appendix C.2. The results show a wide range of relationships among the variables that merit further investigation. However, since the scope of this research is to assess the impact of the monetary policy shocks, we limit our attention to the repo rate. In line with economic theory, the repo rate has an inverse relationship with money supply, inflation, domestic credit extension and economic output across the CMA. The results also show a strong relationship between the variables, especially between inflation and economic growth. The correlation between the repo rate and domestic output for the period under study is about -0.72 for Namibia, Lesotho and Eswatini, while South Africa has -0.69. There is a consistent positive correlation between the repo rate and the lending rate spread that ranges from 0.35 (Eswatini) to 0.76 (Namibia).

\subsection{Stationarity Tests}

A starting point in the analysis of stationarity is to examine the data properties graphically and then confirm it statistically. Figure 5.1 shows a time series plot of macroeconomic variables in the CMA. The first observation is that inflation, money supply, domestic credit and economic output are all upward trending. However, LEN countries experienced volatility in the financial sector following the implementation of South Africa's inflation targeting regime in 2000. The volatility can be attributed to the SARB's interest rate hikes that were aimed towards achieving its inflation target as shown in panel A and G. The upward trends provide a justification for their log transformation to pave the way for the

\footnotetext{
${ }^{1}$ Indexed such that $\mathrm{CPI}_{2010 M 6}=100$
} 
interpretation of the impulse responses as elasticities.

Secondly, since 2000, there have been two major shocks experienced in the financial and real sectors in 2002 - 2003 and 2007 - 2008. During each shock, the effects are more pronounced in the financial sector, with the subtle patterns continuing for several periods after the shock. Compared to external global shocks, there is an apparent lag between the repo rate and the U.S. federal funds rate. This implies that when controlling for exogenous shocks, it is necessary to use lagged terms to account for their delayed impact in the CMA.

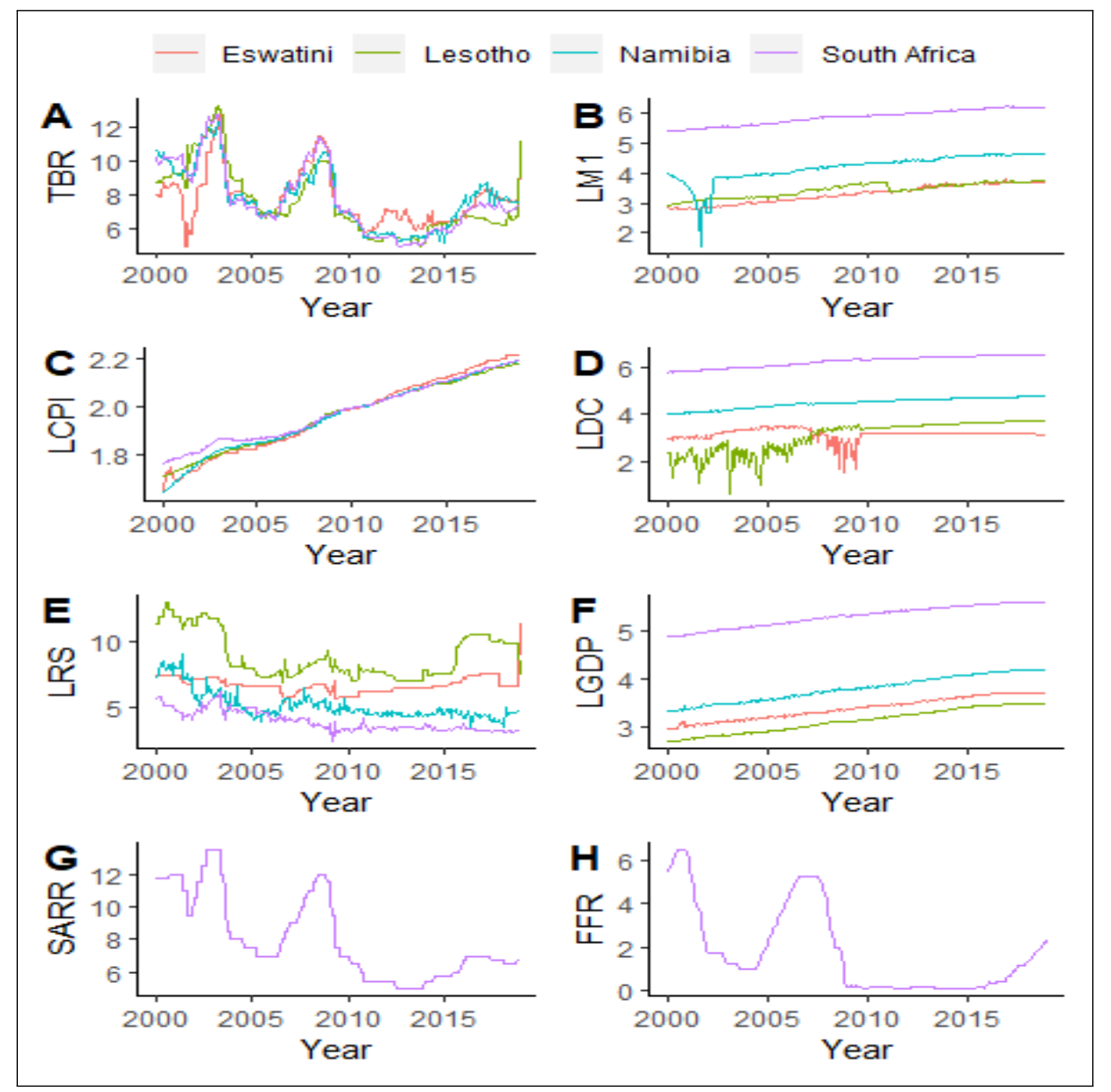

Figure 5.1: Graphical stationarity test at levels, 2000M2-2018M12

Source: South African Reserve Bank, Central Bank of Lesotho, Bank of Namibia, and Central Bank of Eswatini, and the International Monetary Fund.

Finally, the graphical inspection suggests that all variables exhibit non-stationary patterns and thus require differencing to induce stationarity. The results of the ADF and KPSS unit root tests are presented in appendix C.3. Both results confirm that all variables are non-stationary at levels. This means that the time-series 
properties (mean, variance) are not constant. Therefore, it is necessary to difference and then test for stationarity. The test results of the variables at their first differences show that the time series properties are constant. It can be concluded that variables are integrated of order one I(1), and thus they may be included in the model at first differences.

\subsection{Cointegration Tests}

The results from the Johansen cointegration test are presented in appendix C.4. The test results indicate that the null hypothesis of no cointegrating equation is rejected for all countries at the 5 percent significance level. These results raise an important issue about the appropriate model for estimation. One option is to estimate a structural error correction model (SVECM) at first differences. However, this will result in losing part of the information contained in the series due to differencing (Aslanidi, 2007). An alternative approach is to estimate the model at levels. The alternative approach seems plausible, given that the cointegration tests suggest that the residuals are stationary. In fact, Herrera and Pesavento (2013) argue that even if the variables are cointegrated, the most robust form of model specification is to estimate the reduced form VAR at levels. Following the recommendations from Herrera and Pesavento (2013) and Aslanidi (2007), this study estimates the reduced form VAR at levels.

\subsection{Optimal Lag Selection Criteria}

According to the Akaike information criterion (AIC), Schwartz information criterion (SC), the model reporting the lowest $\mathrm{AIC}$ or $\mathrm{SC}$ values is preferred. The results of lag length selection criteria are presented in appendix C.4. The results are mixed. For Eswatini, Namibia and South Africa, the AIC proposes the use of four lags and two lags for Lesotho. In contrast, the SC recommends the selection of one lag for all countries. Given these inconsistencies, the empirical approach is to select the lag length with the lowest value between the two (Lütkepohl and Krätzig, 2004; Shrestha and Bhatta, 2017). Therefore, we proceed with the op- 
timal lag identified by the Schwartz information criterion since it has the lowest value. The maximum lag order of one will be used as it is sufficient enough to render serially uncorrelated VAR errors.

\subsection{Structural VAR Results}

The empirical question we attempt to answer here is: how do real and financial macroeconomic variables in the CMA respond to a sudden change in the monetary policy instrument. For purposes of our analysis, the South African repo rate has been identified as a monetary policy instrument used in the CMA. The effects of monetary policy shocks are examined through the estimated IRFs and FEVDs. The impulse response functions are computed, as shown in equation 4.12. However, the contemporaneous matrix coefficients $\left(\Gamma_{0}\right)$ must first be estimated in order to determine the vector moving average coefficients $\left(\phi_{i}\right)$. The structural VAR is over-identified, and so the usual LR test for over-identification is applied, under the null hypothesis that the restrictions are valid (Kim and Roubini, 2000; Aslanidi, 2007). Table 5.2 shows the identifying restrictions are not rejected at a 5 percent significance level for all countries.

Table 5.2: Likelihood test of over-identifying restriction

\begin{tabular}{rcc}
\hline \hline Country & Chi-square & Significance level \\
\hline Eswatini & $\mathcal{X}^{2}(2)=0.6242$ & 0.732 \\
Lesotho & $\mathcal{X}^{2}(2)=0.4684$ & 0.791 \\
Namibia & $\mathcal{X}^{2}(2)=0.3609$ & 0.835 \\
South Africa & $\mathcal{X}^{2}(2)=1.1840$ & 0.553 \\
\hline
\end{tabular}

Source: Author's own contribution

\subsubsection{Impulse Response Functions}

The impulse responses of economic output, inflation, narrow money supply, domestic credit, and lending rate spread are generated from the SVAR and calculated for an eight-month horizon. Figures 5.2 to 5.6 display the impulse responses of the selected variables to a one per cent positive shock in the repo rate (monetary tightening). For comparison, each figure presents the impulse response functions of a given variable for each CMA member country. Impulse Response graphs contain 
the 90 percent confidence bands about the impulse response function. A response is statistically significant if its computed error bands do not include zero.

Figure 5.2 shows that a positive shock in the repo rate has a statistically significant contractionary effect on economic output in the CMA. In Eswatini, economic output only begins to respond to repo rate shock after the second month and declines briefly by 0.05 percent, before trending upwards after the fifth month. In Namibia, economic output decreases by about 0.04 percent before increasing; however, the significance decreases after the second month. In Lesotho, economic output continues to decline by around 0.06 percent beyond the eight-month horizon. The response in South Africa stabilises after four months after declining by 0.15 percent. These findings are in contrast to (Seleteng, 2016) who found that the response of economic growth in the CMA region to a positive shock in the repo rate is positive and statistically significant for one year only. However, the pattern and speed of adjustment of our results correspond with results from other studies (Buigut (2009) in EAC; Sheefeni and Ocran (2012) in Namibia).

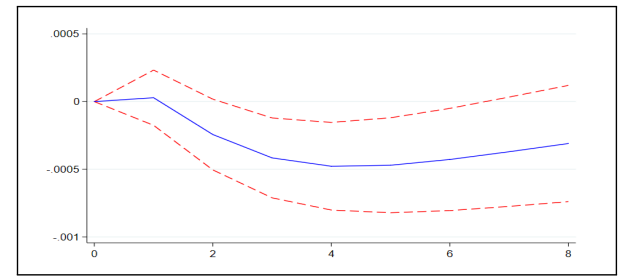

(a) Eswatini

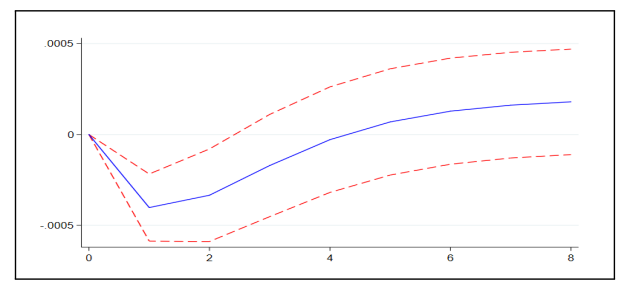

(c) Namibia

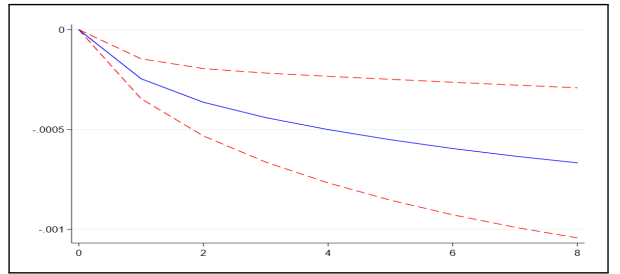

(b) Lesotho

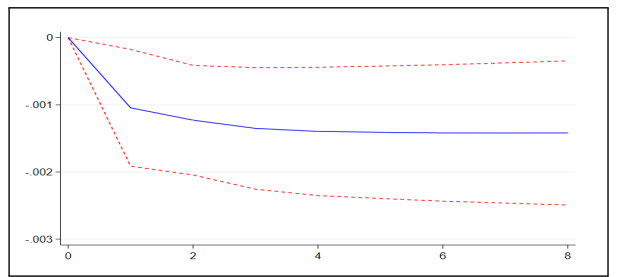

(d) South Africa

Figure 5.2: Economic output responses to a repo rate shock Source: Author's own contribution

The impulse response functions of price levels reveal a significant and contemporaneous effect of repo rate shocks in all countries, as shown in figure 5.3. These results are particularly crucial, given that inflation is a primary target in SouthAfrica's monetary policy conduct. Following a one-time increase in the repo rate 
by one per cent, price levels in South Africa rapidly increase by over 0.1 percent within five months but stabilise after that. In the LEN countries, price levels continue to sluggishly increase by around 0.03 percent beyond the eight-month horizon, with Namibia having the slowest response. These results contradict theoretical expectation from a contractionary monetary policy. These unconventional observations have been extensively investigated in the literature and have been dubbed the price puzzle ${ }^{2}$ (Kim and Roubini, 2000; Leeper, Sims, and Zha, 1996). Ncube and Ndou (2013) have suggested that this puzzle is commonly found when using recursive identification strategies and thus, additional variables that capture future anticipated inflation should be included in the model. However, the U.S. federal reserve funds rate was incorporated in our estimated models to control for exogenous shocks. The results did not significantly change when world oil prices were included. These could be interpreted as a signal that the federal funds rate is not sufficient to explain changes to South Africa's monetary policy. Findings similar to ours have been reported in other studies of the CMA and other developing countries (Buigut, 2009; Ikhide and Uanguta, 2010; Gumata, Kabundi, and Ndou (2013); Seleteng, 2016; Mkhonta, 2018).

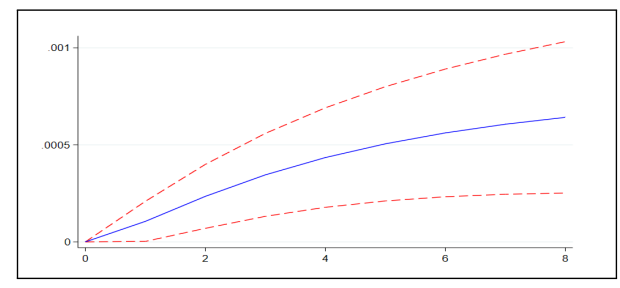

(a) Eswatini

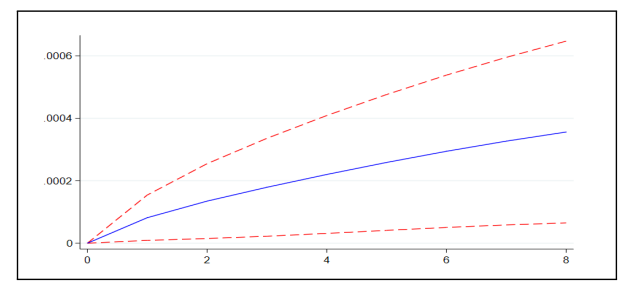

(c) Namibia

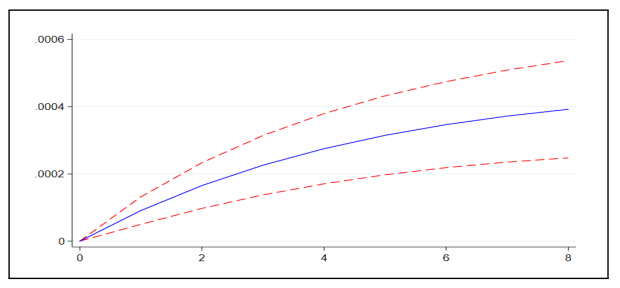

(b) Lesotho

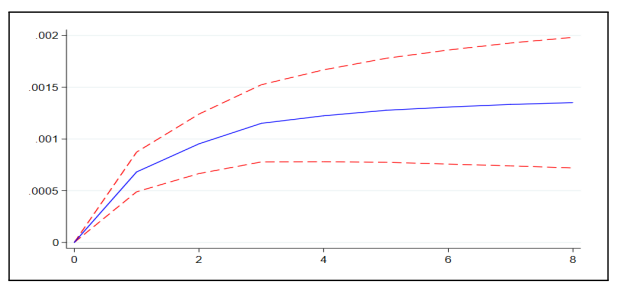

(d) South Africa

Figure 5.3: Inflation responses to a repo rate shock Source: Author's own contribution

\footnotetext{
${ }^{2}$ The price puzzle is described as an effect of the central bank having superior information regarding future economic conditions which leads it to raise interest rates because it expects inflation to rise in the future (Ncube and Ndou, 2013).
} 
The response of narrow money supply due to a positive shock to the repo rate shows conflicting policy outcomes, as shown in figure 5.4. The results are insignificant for Namibia and South Africa. In Eswatini, there is an immediate decline in the money supply by about 0.2 percent that becomes stable after the third month. In contrast, the response in Lesotho is positive and continues persistently upwards by over 0.4 percent. These results suggest that the overall impact of an increase in the repo rate on narrow money supply in the CMA is inconclusive. Economic theory suggests that a positive interest rate shock causes money supply to decrease due to the increased cost of borrowing. Evidence from previous studies in the CMA also reveals that the the effect of interest rate on money supply is inconclusive. Seleteng (2016) and Dlamini and Skosana (2017) found that money supply in the CMA seems to be unresponsive to shocks to the repo rate, while Ikhide and Uanguta (2010) and Gumata, Kabundi, and Ndou (2013) found a negative relationship. Section 5.2.2 will explore the sources of the asymmetric money supply responses in the CMA.

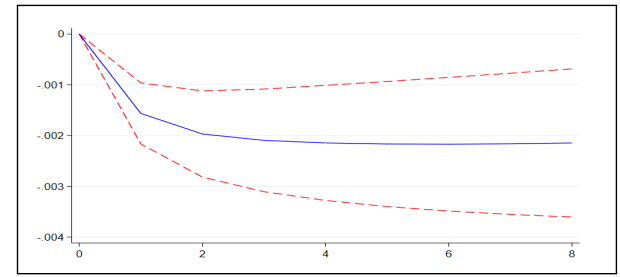

(a) Eswatini

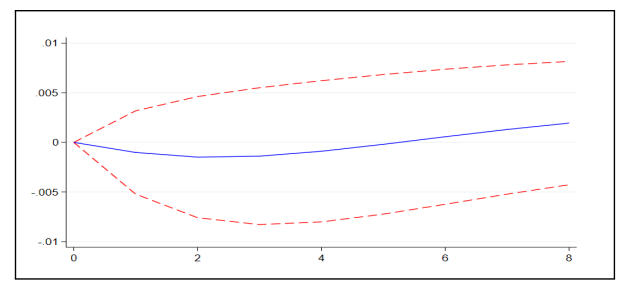

(c) Namibia

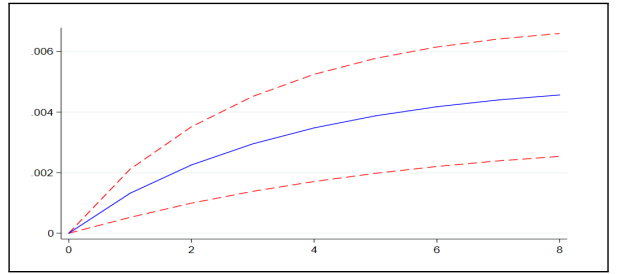

(b) Lesotho

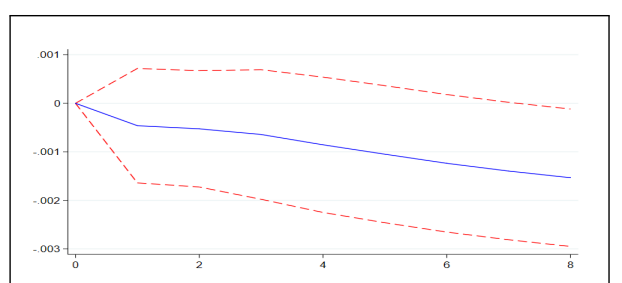

(d) South Africa

Figure 5.4: Money supply responses to a repo rate shock Source: Author's own contribution

Similar to the money supply, the results for domestic credit are not equally optimistic. The responses of domestic credit to a positive change in the repo rate shown in figure 5.5. Domestic credit in South Africa is not responsive changes to the repo rate. In Eswatini, there is a statistically significant contemporaneous 
response of credit to the private sector. It declines sharply by 4 percent but rebounds upwards after the third month. In Lesotho and Namibia, the opposite results are found. Domestic credit responds positively (by 4 percent in Lesotho and 0.8 percent in Namibia) to a change in the repo rate but rebounds downward after the second month. The overall impact of a positive repo rate shock in the CMA, on domestic credit, is inconclusive. Ikhide and Uanguta (2010) and Seleteng (2016) found results similar to ours. In contrast, Gumata, Kabundi, and Ndou (2013) and Dlamini and Skosana (2017) found that a positive shock to the repo rate is immediately followed by a decline in domestic credit.

The results presented in figure 5.4 - 5.5 could be reflective of some of the key challenges facing policymakers in the LEN countries. The banking sector in the LEN countries is characterised by high commercial bank excess reserves. This excess liquidity renders monetary policy ineffective since banks can simply draw on these funds to continue extending credit to borrowers. In a Lesotho case study, Thamae (2014) concluded that excess liquidity in the financial sector is driven by undeveloped financial sector and dominance of the government in economic activities. These results may also reflect the fact that financial developments in Lesotho are lagging behind Eswatini, South Africa, and Namibia.

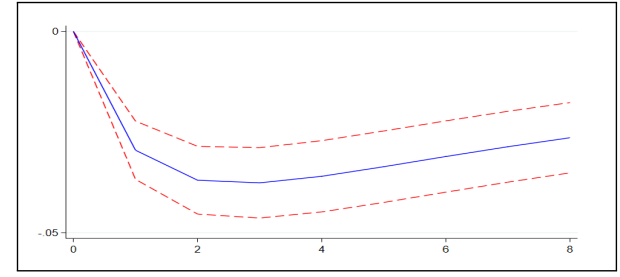

(a) Eswatini

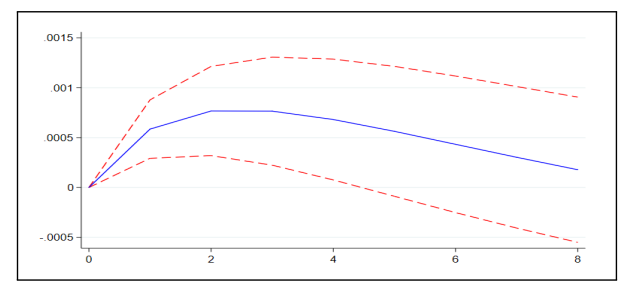

(c) Namibia

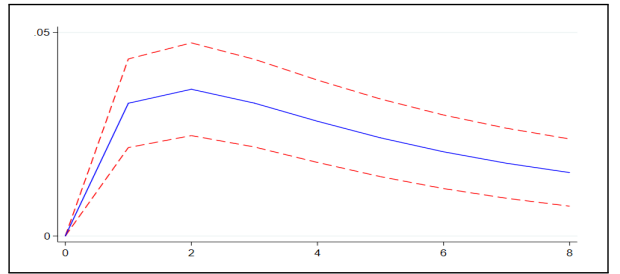

(b) Lesotho

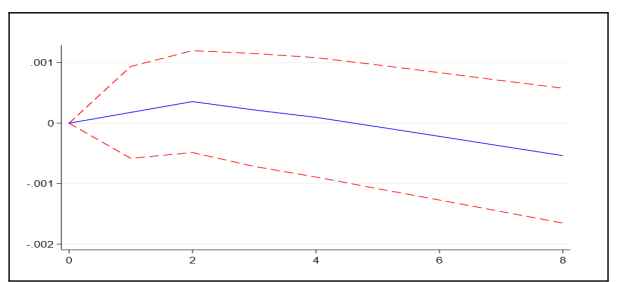

(d) South Africa

Figure 5.5: Domestic credit responses to a repo rate shock Source: Author's own contribution

Finally, figure 5.6 shows the response of lending rate spread to one per cent 
rise in the repo rate. Except Lesotho, lending rate spread responses are found to be significant in the CMA. In Eswatini, lending rate spread continues to increase by over 0.04 percent following innovations to the repo rate. In Namibia, there is a sharp increase by about 0.04 percent but declines after the second month. There is an instantaneous decline in the lending rate spread in South Africa by approximately 0.07 percent, followed by an increase in the second month. It can be concluded that lending rate spread responds positively to monetary policy shocks in the case of the LEN countries. In line with our findings, Ikhide and Uanguta (2010), and Seleteng (2016) found that the response of lending rates to a positive shock on the repo rate is positive and statistically significant. In the case of Lesotho, a possible explanation is that since the lending rates are the highest in the region, an increase in the repo rate will no significantly affect the commercial banks' balance sheets, hence they do not instantly change their lending rates. In South Africa, the results found in Gumata, Kabundi, and Ndou (2013) and Bonga-Bonga (2010) were similar to ours.

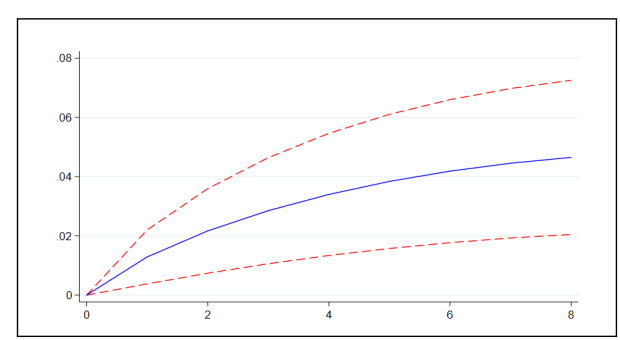

(a) Eswatini

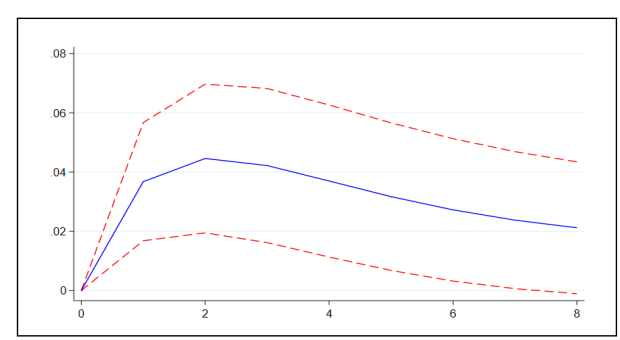

(c) Namibia

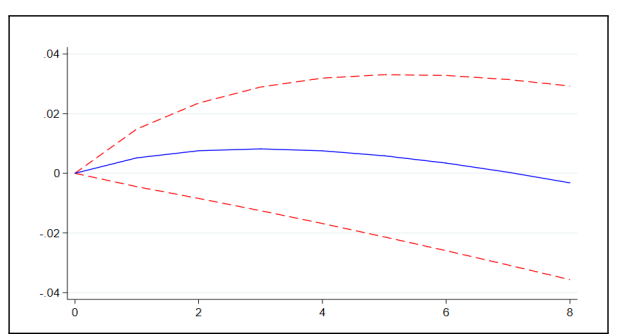

(b) Lesotho

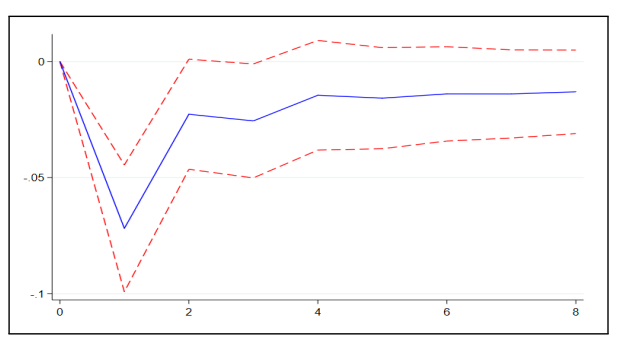

(d) South Africa

Figure 5.6: Lending rate spread responses to a repo rate shock Source: Author's own contribution

The results presented in figure 5.2 - 5.6 show diverse responses to the repo rate shocks in the CMA. Economic output responses show that output in Lesotho continues to decline beyond the eight-month time horizon but remains unchanged 
in the rest of the CMA. The response of inflation shows that after six months, inflation in South Africa remains unchanged while it continues to grow in the LEN countries. The responses of money supply, domestic credit and lending rates are asymmetric in the CMA. This implies, all things being equal, South Africa's monetary policy interventions may have different consequences on these variables in the LEN countries. During periods of economic instability, these asymmetric responses may exacerbate conditions in the LEN countries, exposing them to the risk of further economic downturn. To illustrate this point, let us assume, for example, that South Africa is faced with inflation above the official target range of 6 percent. The SARB will respond by implementing a contractionary monetary policy which increases the repo rate. Our estimated results suggest that this policy action will initially cause a slight increase in inflation, while economic output will slightly decline across all countries in the CMA. In Lesotho and Namibia, our results suggest that money supply and domestic credit will increase in response to this policy change. If additional policy interventions are not implemented in these countries, the increase in money supply and domestic credit will cause inflation to continue rising. Therefore, it is crucial for the LEN countries to develop policy strategies that may help to offset the negative impact of South Africa's monetary policy shocks on their economies.

The results presented in figure 5.4 - 5.6 have revealed some of the problems associated with the CMA regime. Since the ZAR also circulates through the LEN countries, authorities in the LEN do not have full ability to immediately alter the amount of domestic ZAR floating alongside their currencies (Dlamini and Skosana, 2017). The exclusion of the volume of ZAR circulating at any given time in the LENS complicates our understanding of the dynamics of monetary policy in the CMA. Given the high volume of the South African currency circulating in the LEN countries (estimated around 76 percent in 2006-07), the effects of South Africa's policy interventions in the CMA may not be fully captured if the volume of the ZAR is not accounted for. In the next section, we explore some of the factors that 
might have influenced the observed responses to monetary policy shocks.

\subsubsection{Forecast Error Variance Decomposition}

Since the identification of SVAR models is based on theoretical economic expectations, their results alone are considered inadequate. According to Maturu and Ndirangu (2010), the variance decomposition results show the relative importance of a given endogenous variable in explaining the out-of-sample forecast error in another endogenous variable of interest under the analysis. For instance, FEVDs will enable us to characterise the relative importance of the repo rate in explaining the out-of-sample forecast errors in GDP. If a larger proportion of out-of-sample forecast errors in GDP are explained by the repo rate, then there is a greater possibility that the monetary policy instrument is a useful tool. In addition, it is most likely that the corresponding impulse responses will as well be statistically significant and large in magnitude. This implies that variance decomposition results are useful in validating the impulse response function results.

Appendix C.5 presents the forecast error variance decomposition results for all variables in each CMA countries. The shocks have been decomposed into a 24month time horizon. It is evident the variance decomposition results confirm our findings from the impulse response analysis. The results shown in Appendix C.5 can be summarised as follows: Firstly, apart from own shocks, the second most important variable in explaining the forecast errors in economic output during the short time horizon is the repo rate. The repo rate's importance in explaining fluctuations in real economic output increases steadily with time but differs across countries. Secondly, the repo rate is the third most important variable that explains the variance errors in inflation, after itself and economic output. The importance of the repo rate generally remains steady with time, with an exception in Namibia. Lastly, inflation is more important in explaining the fluctuations in the repo rate for South Africa than in the LEN countries. These findings reveal the fact South African authorities do not consider prevalent economic situations in the LEN countries when implementing monetary policy in the CMA. 
The forecast error variance decomposition results may also be useful to explain the sources of asymmetric responses observed in money supply, lending rate spread and domestic credit. The variance decomposition of money supply shows that after a period of 12 months, shocks to the repo rate explain over 20 percent of fluctuations in Lesotho. In Eswatini, Namibia and South Africa, this is less than 10 percent. This suggests that money supply in Lesotho is more sensitive to changes in the repo rate compared to the other LEN countries. Shocks to money supply explain over 10 percent of fluctuations in the lending rate spread in South Africa. This is greater compared to other countries and may explain the observed initial decline in South Africa. The presence of a large informal sector may also be attributed to the observed asymmetrical monetary policy responses. Davoodi, Dixit, and Pinter (2013) argued developing countries in sub-Saharan Africa are characterised by an underdeveloped formal financial market that put constraints on the monetary policy transmission mechanism. 


\section{Robustness AnALYsis}

To ensure robustness of our results, further econometric checks have to be performed on the estimated models. One of the standard tests for robustness in SVAR models is the sensitivity test. This test is performed by re-estimating the model under a different lag structure. The same method of identification which was discussed previously is used, and the number of lags is also chosen according to the lag length criterion tests. The lag selection under this test is based on the AIC results in appendix C.4. That is, we used four lags for Eswatini, Namibia and South Africa's economies while only two lags were used Lesotho's model. The test results presented in Appendix C.6 are in line with our findings, with significant differences in money supply and domestic credit. Contrary to prior our findings where money supply responses were significant for Eswatini and Lesotho, the re-estimated model suggests that money supply in the CMA is insignificantly responsive to innovations to the repo rate at the 90 percent confidence level. The observed inconsistencies may be caused by several factors such as structural breaks, wrong selection of variables etc. However, the fact that all other variables have consistent responses to monetary policy shocks in both models suggests that further robustness tests may be necessary.

Another test for the robustness of the econometric results is the break-point test, where the model over the whole sample period is compared with the model estimated over various sub-samples. In this case, the data series is divided into two parts; the first sub-sample is from the period 2000M2 to 2009M6, the second sub-sample is from the period 2009M7 to 2018M12. Under the same conditions of identification, Appendix C.7 shows the results of the test for each country. The results show that the estimated impulse response patterns of the sub-sample are consistent with the whole sample. This suggests that the estimated results are 
robust to sample size.

Table 6.1: Joint residual heteroskedasticity and normality tests

\begin{tabular}{rccccc}
\hline \hline \multirow{2}{*}{ Country } & \multicolumn{2}{c}{ Normality } & & \multicolumn{2}{c}{ Heteroskedasticity } \\
\cline { 2 - 3 } \cline { 6 - 6 } \cline { 5 - 6 } & Jarque-Bera & Prob. & & Chi-square & Prob. \\
\hline Eswatini & 22.3542 & 0.2835 & & 17.2822 & 0.3676 \\
Lesotho & 16.7221 & 0.5773 & & 14.5703 & 0.5563 \\
Namibia & 12.3066 & 0.6849 & & 16.9862 & 0.3835 \\
South Africa & 18.6076 & 0.4899 & & 22.2764 & 0.1346 \\
\hline
\end{tabular}

Source: Author's own contribution

In addition, the VAR residuals were tested for heteroskedasticity and normality. The results presented in figure 6.1 indicate that the null hypothesis that the residuals are multivariate normal cannot be rejected for all countries. There is no heteroskedasticity in the residuals. Lastly, figure 6.2 shows that the null hypothesis of no correlation at lag order one cannot be rejected at the 5 percent significance level.

Table 6.2: Lagrange-Multiplier test for serial autocorrelation

\begin{tabular}{rccc}
\hline \hline & Chi-square & Lags & Significance level \\
\hline Eswatini & $\mathcal{X}^{2}(49)=57.6425$ & 1 & 0.1860 \\
Lesotho & $\mathcal{X}^{2}(49)=64.2429$ & 1 & 0.1467 \\
Namibia & $\mathcal{X}^{2}(49)=56.0724$ & 1 & 0.2268 \\
South Africa & $\mathcal{X}^{2}(49)=55.0792$ & 1 & 0.2556 \\
\hline
\end{tabular}

Source: Author's own contribution 


\section{Discussion AND Conclusion}

The objective of this paper is to examine the effect of monetary policy shocks on the Common Monetary Area. The LEN currencies are fixed to the South African rand, and capital flows between countries are tariff-free. However, the CMA cannot be characterised as a fully-fledged monetary union since monetary policy is set independently in South Africa. Interest rates in the LEN countries cannot deviate too far from those in South Africa. As a result, the South African repo rate is the relevant monetary policy instrument in the region. The effect of unexpected monetary policy shocks has remained largely unresolved, especially in developing countries. There is a limited number of studies on the monetary policy transmission mechanism in developing countries compared to industrialised countries. The current literature on monetary policy transmission mechanism in the CMA differs in their results depending on various aspects like model specification, the econometric technique used, variable selection and the period under study.

This study comparatively evaluates the effect of shocks to the South African repo rate on the LEN economies. Our analysis is based on a six-variable structural VAR model estimated using monthly data for the period 2000 to 2018. Due to data limitations, the study applied a Chow-Lin temporal disaggregation method to interpolate monthly economic output. Unlike previous studies in the CMA, the U.S. federal funds rate was used to control for changes due to external factors. In addition, the study focused primarily on the period following the implementation of the inflation targeting regime to better reflect short-run dynamics of monetary policy.

Our findings suggest that an exogenous and temporary increase in the South African repo rate tends to be followed by a statistically significant decline in output and a rise in price levels for all countries in the CMA. The magnitude of the 
impact varies by country, with South Africa experiencing a significant decrease in output and an increase in price levels. These results seem to be stable over different sample periods. The findings also showed that the effect of monetary policy shocks on domestic credit, lending rate spread and money supply is asymmetric across the CMA. These findings suggest that monetary policy interventions employed in South Africa may have a negative effect on the financial sector in the LEN countries. If further policy strategies are not implemented in the LEN countries to offset these effects, economic conditions in the LEN countries may continue to worsen. The empirical literature suggests several factors that might have contributed to the observed asymmetric responses in the CMA. One of the causes might be the underdevelopment of the financial markets and, hence, the weak transmission of financial signals to commercial banks, investors and consumers. The presence of informal markets in the CMA is also a source of concern in the transmission of monetary policy. Given the large size of informal economies, national account statistics may not fully reflect the dynamics of monetary policy. The paucity of data on the total volume of the South African currency circulating in the LEN countries may have also affected our results, particularly the response of narrow money supply.

\subsection{Policy Recommendations}

Our results suggest that it is important for the South African authorities to pay close attention to the economic conditions in the LEN countries when implementing monetary policy in order to avoid exacerbating economic instability in the LEN countries. The LEN countries are also recommended to improve measures to estimate the volume of the ZAR circulation their respective economies through regular monetary surveys. This will provide a more accurate estimation of the dynamics of monetary policy in the LEN countries. Improving the efficacy of monetary policy in the CMA may require addressing these issues and, among others, ensuring that monetary targets and interest rate policy are consistent among all members. 


\subsection{Limitations AND FURTHER RESEARCH}

This study suffers from several limitations that may be addressed by future research. Firstly, our model does not include any measures of fiscal policy and exchange rate, which may have an effect on the monetary policy shocks in the CMA. Secondly, our research focused only on monetary policy shocks. It could also be interesting to explore the effects of output shocks, demand shocks and supply shocks in the CMA. Thirdly, Gumata, Kabundi, and Ndou (2013) have argued that the transmission of monetary policy shocks in South Africa has changed since the 2008 global financial crisis. Although our results showed robustness to the break-point test, future research could estimate the transmission of South Africa's monetary policy shocks to the LEN countries using data from the period after the recession. 


\section{REFERENCES}

Ajilore, Taiwo, and Sylvanus Ikhide. 2013. "Monetary policy shocks, output and prices in South Africa: a test of policy irrelevance proposition". The Journal of Developing Areas 47 (2): 363-386.

Alweendo, Tom. 2000. "The challenges of monetary policy for Namibia within the common monetary arrangement". In The Bankers Conference, 4-6. Bank of Namibia.

Arestis, Philip, and Malcolm Sawyer. 2003. "Can Monetary Policy Affect The Real Economy?"

Aron, Janine, and John Muellbauer. 2007. "Review of Monetary Policy in South Africa since 1994". Journal of African Economies 16, no. 5 (): 705-744.

Aslanidi, Olga. 2007. "The Optimal Monetary Policy and the Channels of Monetary Transmission Mechanism in CIS-7 Countries: The Case of Georgia". Czech Republic.

Bank of Namibia. 2008. Namibia's Monetary Policy Framework. Tech. rep. Bank of Namibia.

Bernanke, Ben S. 1986. "Alternative explanations of the money-income correlation". Carnegie-Rochester Confer. Series on Public Policy 25, no. C (): 49-99. ISSN: 01672231. doi:10.1016/0167-2231 (86)90037-0.

Bernanke, Ben, and Mark Gertler. 1995. "Inside the Black Box: The Credit Channel of Monetary Policy Transmission".

Bernanke, Ben, and Frederic Mishkin. 1997. "Inflation Targeting: A New Framework for Monetary Policy?" Journal of Economic Perspectives (Cambridge, MA) 11, no. 2 (): 97-116.

Blanchard, Olivier, and Mark Watson. 1984. "Are Business Cycles All Alike?" Chicago, IL. 
Bonga-Bonga, Lumengo. 2010. "Monetary Policy And Long-Term Interest Rates In South Africa". International Business 86 Economics Research Journal (IBER) $9(10): 43-54$.

Bonga-Bonga, Lumengo, and Alain Kabundi. 2015. Monetary Policy Instrument and Inflation in South Africa: Structural Vector Error Correction Model Approach. Germany.

Buigut, Steven. 2009. "Monetary Policy Transmission Mechanism: Implications for the Proposed East African".

Central Bank of Lesotho. 2019. CBL Monetary Policy. https://www . centralbank. org.ls/index.php/monetary-policy/cbl-monetary-policy.

Central Bank of Swaziland. 2017. Swaziland's monetary policy framework economic. Tech. rep.

Chatterjee, Satyajit. 2002. "The Taylor Curve and the Unemployment-Inflation Tradeoff'. In Business Review, Federal Reserve Bank of Philadelphia, 26-33. 3. Philadelphia: Federal Reserve Bank of Philadelphia.

Cheng, Kevin C. 2006. "A VAR Analysis of Kenya's Monetary Policy Transmission Mechanism: How Does the Central Bank's REPO Rate Affect the Economy?" IMF Working Papers 06 (300).

Chow, Gregory C, and An-Loh Lin. 1971. "Best Linear Unbiased Interpolation, Distribution, and Extrapolation of Time Series by". Source: The Review of Economics and Statistics 53 (4): 372-375.

Coco, Alberto, and Nicola Viegi. 2019. "The monetary policy of the South African Reserve Bank: stance, communication and credibility".

Collings, Francis d'A. 1978. "The Rand and the Monetary Systems of Botswana, Lesotho, and Swaziland". Source: The Journal of Modern 1African Studies 16 (1): $97-121$.

Cooley, Thomas F., and Stephen F. Leroy. 1985. "Atheoretical macroeconometrics: A critique". Journal of Monetary Economics 16, no. 3 (): 283-308.

Davoodi, Hamid R., Shiv Dixit, and Gabor Pinter. 2013. "Monetary Transmission Mechanism in the East African Community: An Empirical Investigation". 
Denton, Frank T. 1971. "Adjustment of Monthly or Quarterly Series to Annual Totals: An Approach Based on Quadratic Minimization". Journal of the American Statistical Association 66, no. 333 (): 99-102.

Dlamini, Bongani, and Sipho Skosana. 2017. Relationship and Causality between Interest Rates and Macroeconomic Variables in Swaziland. Tech. rep. Central Bank of Swaziland.

Famoroti, Jonathan Olusegun, and Christian K Tipoy. 2019. Macro economic effects of external monetary policy shocks to economic growth in West Africa.

Friedman, Milton. 1968. "The Role of Monetary Policy". American Economic Association 58 (1): 1-17.

Gedikli, Ayfer. 2017. "Monetary Transmission Mechanism: An Overview Explanation". Igd Univ Jour Soc Sci, no. 13: 472-517.

Gumata, Nombulelo, Alain Kabundi, and Eliphas Ndou. 2013. "Important channels of transmission monetary policy shock in South Africa". South African Reserve Bank Working Paper Series 06 (06).

Herrera, Ana María, and Elena Pesavento. 2013. "Unit Roots, Cointegration and Pre-Testing in VAR Models". Advances in Econometrics 32 (4): 81-115.

Hicks, J R. 1937. "Mr. Keynes and the "Classics"; A Suggested Interpretation". Econometrica 5 (2): 147-159.

Ikhide, Sylvanus, and Ebson Uanguta. 2010. "Impact of South Africa's Monetary Policy on the LNS Economies". Journal of Economic Integration 25 (2): 324352.

Ireland, Peter N. 2005. "The Monetary Transmission Mechanism".

Ishioro, Bernhard Ozofere. 2013. "Monetary transmission mechanism in Nigeria: A causality test". Mediterranean Journal of Social Sciences 4, no. 13 (): 377-388.

Iwata, Shigeru, and Shu Wu. 2006. "Estimating monetary policy effects when interest rates are close to zero". Journal of Monetary Economics 53:1395-1408.

Johansen, Søren. 1988. "Statistical analysis of cointegration vectors". Journal of Economic Dynamics and Control 12, no. 2 (): 231-254. 
Johansen, Søren, and Katarina Juselius. 1990. "Maximum Likelihood Estimation and Inference on Cointegration-With Applications to the Demand for Money". Oxford Bulletin of Economics and Statistics 52, no. 2 (): 169-210.

Kalenga, Paul. 2001. "Monetary policy framework in Namibia". In Conference on Monetary Policy Frameworks in Africa.

Karan, Alisha. 2013. "Quarterly Output Indicator Series for Fiji".

Kim, Soyoung, and Nouriel Roubini. 2000. "Exchange rate anomalies in the industrial countries: A solution with a structural VAR approach". Journal of Monetary Economics, no. 45: 561-586.

Leeper, Eric M, Christopher A Sims, and Tao Zha. 1996. "What Does Monetary Policy Do?" Brookings Papers on Economic Activity 27 (2): 1-78.

Litterman, Robert B. 1983. "A Random Walk, Markov Model for the Distribution of Time Series". Journal of Business \& Economic Statistics 1 (2): 169-173.

Loayza, Norman, and Klaus Schmidt-Hebbel. 2002. "Monetary Policy Functions and Transmission Mechanisms: An Overview".

Lütkepohl, Helmut. 2005. New Introduction to Multiple Time Series Analysis. 1st ed. Berlin: Springer Verlag.

Lütkepohl, Helmut, and Markus Krätzig. 2004. Applied time series econometrics. 1st. 1-323. Cambridge University Press.

Maturu, Benjamin, and Lydia Ndirangu. 2010. "Monetary Policy Transmission Mechanism in Kenya: A Bayesian Vector Auto-regression (BVAR) Approach".

Metzger, Martina. 2004. "The Common Monetary Area in Southern Africa: A Typical South-South Coordination Project?" The Berlin Institute for Financial Market Research: 147-164.

Meyer, Daniel, Jacques De Jongh, and Devan Van Wyngaard. 2018. "An Assessment of the Effectiveness of Monetary Policy in South Africa". Acta Universitatis Danubius. Economica 14 (6). ISSN: 2067-340X.

Mirdala, Rajmund. 2009. "Shocking aspects of monetary integration ( SVAR approach )". Journal of Applied Research in Finance 1 (1).

Mishkin, Frederic. 1995. "Symposium on the Monetary Transmission Mechanism". Journal of Economic Perspectives 9 (4): 3-10. 
- . 2014. The Economics of Money, Banking and Financial Markets. 11th ed., 53:1689-1699. 9. New-York.

Mkhonta, Simiso F. 2018. "Discount Rate Differential Monetary Policy Decisions in the CMA and Portfolio Investment Assets: The Efficacy of Namibia and Swaziland Monetary Policy". Research Bulletin - Central Bank of Swaziland 2.

Mosikari, Teboho Jeremiah, and Joel Hinaunye Eita. 2018. Estimating threshold level of inflation in Swaziland: inflation and growth. Tech. rep.

N'Diaye, Papa M'B. P., and Douglas Laxton. 2002. "Monetary Policy Credibility and the Unemployment-Inflation Tradeoff: Some Evidence From 17 Industrial Countries".

Ncube, Mthuli, and Eliphas Ndou. 2013. "Effects of Monetary Policy on Output". Chap. 3 in Monetary Policy and the Economy in South Africa, 1st ed., 9-24. Palgrave Macmillan.

Ndubuisi, Gideon Onyewuchi. 2015. "Interest Rate Channel of Monetary Policy Transmission Mechanisms: What Do We Know About it?" SSRN Electronic Journal, no. i: 1-14.

Peersman, Gert, and Frank Smets. 2001. "The monetary transmission mechanism in the euro area: more evidence from VAR analysis".

Sax, Christoph, and Peter Steiner. 2013. "Temporal Disaggregation of Time Series". The $R$ Journal 5 (2).

Seleteng, Monaheng. 2016. "Effects of South African Monetary Policy Implementation on the CMA: A Panel Vector Autoregression Approach".

- 2005. Inflation and Economic Growth: An estimate of an optimal level of inflation in Lesotho. Tech. rep. Central Bank of Lesotho.

Sheefeni, J P S, and M K Ocran. 2012. "Monetary policy transmission in Namibia: A review of the interest rate channel". Journal for Studies in Economics and Econometrics 36 (3): 47-63.

Shrestha, Min Bahadur, and Guna Raj Bhatta. 2017. "Selecting Appropriate Methodological Framework for Time Series Data Analysis".

Sims, Christopher A. 1986. "Are Forecasting Models Usable for Policy Analysis?" Federal Reserve Bank of Minneapolis Quarterly Review 1 (10): 2-16. 
—. 1980. "Macroeconomics and Reality". Econometrica 48 (1): 1-48.

Smets, Frank, and Raf Wouters. 2003. "An Estimated Stochastic Dynamic General Equilibrium Model of the Euro Area". Journal of the European Economic Association 1 (5): 1123-1175.

Taylor, John B. 1995. "The Monetary Transmission Mechanism: An Empirical Framework". Journal of Economic Perspectives 9 (4): 11-26.

Thamae, Matsabisa. 2014. Excess Liquidity in the Financial Sector of Lesotho: Main Drivers and Policy Options. Wits Business School.

The Economist. 2015. Monetary policy committee establishes repurchase rate.

Tjirongo, Meshack Tunee. 1995. "Short-Term Stabilisation Versus Long-Term Price Stability: Evaluating Namibia's Membership of the Common Monetary Area".

Twinoburyo, Enock Nyorekwa, and Nicholas M. Odhiambo. 2018. "Monetary policy and economic growth: A review of international literature". Journal of Central Banking Theory and Practice 7 (2): 123-137.

Van den Heever, Johan. 2010. "External Use of the South African Rand". In Currency internationalization : global experiences and implications for the Renminbi, ed. by Wensheng Peng and Chang Shu, 42-55. London: Palgrave Macmillan. ISBN: 9780230580497.

Wang, Jian-Ye, et al. 2007. "The Common Monetary Area in Southern Africa: Shocks, Adjustment, and Policy Challenges".

Zha, Tao. 1997. "Identifying Monetary Policy: A Primer". Economic Review- Federal Reserve Bank of Atlanta 2 (82): 26-43.

Zivot, Eric, and Jiahui Wang. 2005. Modelling Financial Time Series with S-PLUS. 2nd ed. 


\title{
APPENDiX A
}

\section{A.1 Definition of Variables}

\author{
Abbreviations of variables \\ SARR: South Africa's Repo Rate \\ LM1: Log of Narrow Money Supply \\ LCPI: Log of Consumer Price Index \\ LDC: Log of Domestic Credit \\ LRS: Lending Rate Spread \\ LGDP: Log of Gross Domestic Product
}

Repo Rate: It is a short-term rate at which a central bank discounts or re-discounts the various classes of bills, promissory notes and other securities to meet liquidity needs of commercial banks.

Money Supply (M1): The is the sum of physical currency in the hands of the public and checkable deposits held in commercial banks. It is regarded the narrowest definition of money in the sense that it reflects the most liquid form of financial assets.

CPI/Inflation: It is an index that measures how prices of consumer goods have changed over a given period of time. It is calculated by comparing the prices of a fixed basket of goods and services between two intervals.

Domestic Credit: This reflects the total financial resources provided to the private sector by financial institutions (banks, pension funds, money lenders i.e.)

Lending Rate Spread: This is the difference between lending rate and deposit rate. Lending rate is defined as the rate at which commercial banks lend money to individuals and businesses to meet their short-term financial needs. This rate is typically depends on creditworthiness of borrowers and objectives of financing. Deposit rate is defined as the interest rate paid out by commercial banks to account holders on cash deposits held at the bank. The rate depends on multiple factors such as the amount of cash deposited and the type of account.

Economic Output: This represents the total market value of final goods and 
services produced in a country in a given time period. This accounts only for both market and non-market activities that can be statistically measured/estimated. 


\section{APPENDIX B}

\section{B.1 History of the Common Monetary Area}

Wang et al. (2007) have provided the following summary of events in the CMA:

\section{Table 1: A timeline of major events in the CMA history}

- Before 1960 An informal monetary union with South African pound as a common currency

- 1960s South African pound was replaced by the South African Rand (ZAR). Eswatini and Lesotho become independent from Britain.

- 1974 Eswatini, Lesotho, and South Africa signed the Rand Monetary Area Agreement. The agreement allowed Eswatini to issue its national currency, Eswatini Lilangeni (SZL), pegged at par to the ZAR.

- 1980 Lesotho established its central bank and started to issue its national currency, Lesotho Loti (LSL), pegged at par to the ZAR

- 1986 RMA was replaced by CMA. Additional provisions regarding capital control, seigniorage compensation and intra-CMA funds transfers were made. Eswatini prohibited the use of ZAR within its boarders.

- 1989 Exchange restrictions that were due to limitations on conversion of balances upon termination of one member were lifted from the CMA agreement.

- 1990s South Africa and Namibia both became independent. Namibia formally joined the CMA in 1990 and subsequently issued its own curreny, pegged at par to the ZAR.

- 2000 The South African Reserve Bank adopted an inflation targeting framework.

- 2003 Eswatini re-authorised the circulation of the ZAR alongside the SZL.

\section{B.2 Institutional Arrangement of the CMA}

Collings (1978) and Tjirongo (1995) have highlighted the following aspects of the CMA arrangement: 
1. Currency Arrangement: Under the CMA agreement Lesotho, Eswatini, and Namibia (LEN) have the right to issue their national currencies only within their jurisdiction. The bilateral agreements between South Africa and the three member countries specifies areas, in addition to South Africa, where the ZAR is a legal tender. Currently, the ZAR is a legal tender throughout the CMA. The bilateral agreements also require the LEN countries to permit authorised dealers within their boarders to convert their currencies at par with the ZAR without any restrictions. There is a clearing system that repatriates ZAR coins and banknotes circulating in the other member countries. The central banks of Lesotho and Namibia are required back their currency issues by a mixture of South African Rand assets ${ }^{\ddagger}$. Such assets may include: 1) the central bank's holdings of rand balances, 2) the ZAR currency the central bank holds in a Special Rand Deposit Account with the SARB, 3) South African government stocks, 4) Investments in South Africa's Corporation for Public Deposit.

2. Flow of Funds Inside the CMA: There are no legal restrictions imposed on transfer of funds (current and capital) to or from a member country. The only exception is that member countries have control over investment and liquidity requirements for financial institutions within their boarders. These regulations require financial institutions to invest funds in domestic securities or extend credit to local businesses and individuals. The purpose of these regulations is to address the concern that funds generated in the LEN and deposited with local financial institutions tended to flow to the more developed capital markets in South Africa.

3. Access to South African Financial Markets: The agreement provides the LEN countries with access to South African financial markets, but only through authorised investments channels or securities that can be held in financial institutions in South Africa. However, there are currently no arrangements for South Africa to participate in short-term money markets (treasury bills, t-bonds e.t.c) issued by the LEN countries. Under special

\footnotetext{
${ }^{\ddagger}$ Eswatini was not included in this agreement in part due to events in 1986, see appendix 7 . for more details.
} 
circumstances, the LEN countries can enter into bilateral negotiations with South Africa to obtain temporary bank credit. The SARB therefore acts as a lender of last in order to maintain financial stability within the CMA.

4. Management of Gold and Foreign Exchange Transactions: Under article 5 of the CMA, respective central banks have responsibility over management of gold and foreign exchange reserves. In order to enable the SARB to keep track of the exchange control system, the LEN countries are required to surrender their gold and foreign exchange receipts of residents to South African authorities. The exchange control regulations of the LEN are required to be similar to those in practice in South Africa which are amended from time to time.

5. Compensatory Payments: Due to forgone seigniorage by the LEN countries, article 6 provides a formula for determining compensation payments that represent a return on the ZAR circulating within their national borders. The formula is given by: $S=\left(\frac{2}{3}\right)\left(i^{\text {bondyield }}\right) \cdot\left(c u^{R}\right)$, where $\left(i^{\text {bondyield }}\right)$ is the annual yield on the most recently issued long-term South-African government stock, $c u^{R}$ is the estimated volume of ZAR circulating within a member country. The $2 / 3$ ratio was established on the assumption that it approximates the yield of a portfolio of reserve assets comprising both long-term and short-term maturities.

6. Consultations and other Provisions: All member are obliged to jointly work together to avoid disruptive capital flows arising as a result of policy implementation in the CMA. The member countries have established a commission to facilitate with policy implementation and consultation. The commission holds regular consultations with the aim of attuning the interest of member countries on common issues pertaining to monetary and foreign exchange control policies. There is a tribunal established to adjudicate disputes that may arise. 


\section{Appendix C}

\section{C.1 CMA Descriptive Statistics, 2000M2-2018M12}

Panel I: Eswatini

\begin{tabular}{rccccc}
\hline \hline Statistic & LM1 & LCPI & LDC & LRS* & LGDP \\
\hline Mean & 3.30 & 1.97 & 3.16 & 6.68 & 3.39 \\
St. Dev. & 0.30 & 0.16 & 0.26 & 0.62 & 0.23 \\
Max & 3.78 & 2.22 & 3.53 & 11.50 & 3.72 \\
Min & 2.78 & 1.64 & 1.53 & 5.40 & 2.95 \\
Skewness & -0.15 & -0.08 & -3.12 & 2.10 & -0.10 \\
Jarque-Bera & 18.25 & 14.25 & 2469.16 & 2144.78 & 14.49 \\
Probability & 0.000 & 0.004 & 0.000 & 0.000 & 0.001 \\
\hline
\end{tabular}

Panel II: Lesotho

\begin{tabular}{rccccc}
\hline \hline Statistic & LM1 & LCPI & LDC & LRS* & LGDP \\
\hline Mean & 3.43 & 1.96 & 3.08 & 8.96 & 3.13 \\
St. Dev. & 0.23 & 0.14 & 0.67 & 1.77 & 0.25 \\
Max & 3.73 & 2.18 & 3.74 & 13.17 & 3.48 \\
Min & 2.23 & 1.71 & 0.64 & 6.83 & 2.70 \\
Skewness & -0.41 & -0.14 & -1.10 & 0.71 & -0.08 \\
Jarque-Bera & 19.32 & 15.60 & 47.34 & 119.20 & 17.22 \\
Probability & 0.000 & 0.000 & 0.000 & 0.000 & 0.000 \\
\hline
\end{tabular}

Panel III: Namibia

\begin{tabular}{rccccc}
\hline \hline Statistic & LM1 & LCPI & LDC & LRS* & LGDP \\
\hline Mean & 4.19 & 1.96 & 4.47 & 5.10 & 3.79 \\
St. Dev. & 0.45 & 0.15 & 0.22 & 1.12 & 0.27 \\
Max & 4.66 & 2.19 & 4.76 & 9.08 & 4.19 \\
Min & 1.56 & 1.64 & 3.98 & 3.23 & 3.33 \\
Skewness & -2.02 & -0.23 & -0.61 & 1.53 & -0.07 \\
Jarque-Bera & 526.30 & 11.01 & 20.28 & 119.20 & 15.47 \\
Probability & 0.000 & 0.004 & 0.000 & 0.000 & 0.000 \\
\hline
\end{tabular}

${ }^{*}$ LRS and SARR are expressed in percentages while LM1, LCPI, LDC and LGDP are log transformations. 
Panel IV: South Africa

\begin{tabular}{rcccccc}
\hline \hline Statistic & LM1 & LCPI & LDC & LRS* & LGDP & SARR $^{*}$ \\
\hline Mean & 5.85 & 1.98 & 6.23 & 3.86 & 5.29 & 8.03 \\
St. Dev. & 0.25 & 0.12 & 0.23 & 0.79 & 0.22 & 2.52 \\
Max & 6.21 & 2.19 & 6.54 & 6.24 & 5.60 & 13.50 \\
Min & 5.40 & 1.76 & 5.78 & 2.30 & 4.49 & 5.00 \\
Skewness & -0.29 & 0.09 & -0.46 & 0.84 & -0.29 & 0.71 \\
Jarque-Bera & 16.69 & 15.37 & 21.29 & 27.55 & 16.61 & 25.61 \\
Probability & 0.000 & 0.000 & 0.000 & 0.000 & 0.000 & 0.000 \\
\hline
\end{tabular}

\section{C.2 Correlation Matrices}

Panel I: Eswatini

\begin{tabular}{rcccccc}
\hline \hline & LM1 & LCPI & LDC & LRS & LGDP & SARR \\
\hline LM1 & 1.00 & & & & & \\
LCPI & 0.99 & 1.00 & & & & \\
LDC & -0.03 & -0.05 & 1.00 & & & \\
LRS & -0.11 & -0.06 & -0.05 & 1.00 & & \\
LGDP & 0.99 & 0.99 & -0.02 & -0.07 & 1.00 & \\
SARR & -0.76 & -0.72 & -0.29 & 0.35 & -0.73 & 1.00 \\
\hline
\end{tabular}

Panel II: Lesotho

\begin{tabular}{rcccccc}
\hline \hline & LM1 & LCPI & LDC & LRS & LGDP & SARR \\
\hline LM1 & 1.00 & & & & & \\
LCPI & 0.93 & 1.00 & & & & \\
LDC & 0.88 & 0.88 & 1.00 & & & \\
LRS & -0.40 & -0.37 & -0.40 & 1.00 & & \\
LGDP & 0.92 & 1.00 & 0.87 & -0.35 & 1.00 & \\
SARR & -0.61 & -0.72 & -0.58 & 0.68 & -0.72 & 1.00 \\
\hline
\end{tabular}

Panel III: Namibia

\begin{tabular}{rcccccc}
\hline \hline & LM1 & LCPI & LDC & LRS & LGDP & SARR \\
\hline LM1 & 1.00 & & & & & \\
LCPI & 0.83 & 1.00 & & & & \\
LDC & 0.86 & 0.98 & 1.00 & & & \\
LRS & -0.70 & -0.78 & -0.82 & 1.00 & & \\
LGDP & 0.83 & 0.99 & 0.97 & -0.75 & 1.00 & \\
SARR & -0.61 & -0.73 & -0.77 & 0.76 & -0.73 & 1.00 \\
\hline
\end{tabular}


Panel IV: South Africa

\begin{tabular}{rcccccc}
\hline \hline & LM1 & LCPI & LDC & LRS & LGDP & SARR \\
\hline LM1 & 1.00 & & & & & \\
LCPI & 0.98 & 1.00 & & & & \\
LDC & 0.99 & 0.97 & 1.00 & & & \\
LRS & -0.87 & -0.83 & -0.90 & 1.00 & & \\
LGDP & 1.00 & 0.98 & 0.99 & -0.87 & 1.00 & \\
SARR & -0.72 & -0.69 & -0.72 & 0.70 & -0.74 & 1.00 \\
\hline
\end{tabular}

\section{C.3 Unit Root Tests}

Panel I: ADF test results by country, 2000M2-2018M12

\begin{tabular}{|c|c|c|c|c|c|c|}
\hline & \multirow{2}{*}{ Country } & \multicolumn{2}{|c|}{ Levels } & \multicolumn{2}{|c|}{ First Differences } & \multirow{2}{*}{ Decision } \\
\hline & & Constant & Trend & Constant & Trend & \\
\hline \multirow{4}{*}{ LM1 } & ESW & -0.94 & -2.18 & $-11.50^{* * *}$ & $-11.51^{* * *}$ & $\mathrm{I}(1)$ \\
\hline & LES & -1.72 & -2.31 & $-9.44^{* * *}$ & $-9.48^{* * *}$ & $\mathrm{I}(1)$ \\
\hline & NAM & -1.84 & $-3.97^{* * *}$ & $-11.55^{* * *}$ & $-11.53^{* * *}$ & $\mathrm{I}(1)$ \\
\hline & RSA & -1.66 & -0.0 .79 & $-9.31^{* * *}$ & $-9.47^{* * *}$ & $\mathrm{I}(1)$ \\
\hline \multirow{4}{*}{ LCPI } & ESW & -0.20 & $-3.22^{*}$ & $-10.42^{* * *}$ & $-10.34^{* * *}$ & $\mathrm{I}(1)$ \\
\hline & LES & -1.96 & -1.33 & $-6.94^{* * *}$ & $-7.21^{* * *}$ & $\mathrm{I}(1)$ \\
\hline & NAM & $-3.37^{* *}$ & $-4.37^{* * *}$ & $-5.55^{* * *}$ & $-5.99^{* * *}$ & $\mathrm{I}(1)$ \\
\hline & $\mathrm{RSA}$ & -0.32 & -1.92 & $-5.91^{* * *}$ & $-5.89^{* * *}$ & $\mathrm{I}(1)$ \\
\hline \multirow{4}{*}{$\mathrm{LDC}$} & ESW & $-2.94^{* *}$ & -2.95 & $-15.38^{* * *}$ & $-15.35^{* * *}$ & $\mathrm{I}(1)$ \\
\hline & LES & -1.95 & $-3.36^{*}$ & $-11.38^{* * *}$ & $-11.38^{* * *}$ & $\mathrm{I}(1)$ \\
\hline & NAM & $-4.93^{* * *}$ & -1.43 & $-7.47^{* * *}$ & $-8.28^{* * *}$ & $\mathrm{I}(1)$ \\
\hline & $\mathrm{RSA}$ & $-2.78^{*}$ & -0.74 & $-6.96^{* * *}$ & $-7.36^{* * *}$ & $\mathrm{I}(1)$ \\
\hline \multirow{4}{*}{ LRS } & ESW & -1.26 & -1.04 & $-4.59^{* * *}$ & $-4.72^{* * *}$ & $\mathrm{I}(1)$ \\
\hline & LES & -1.85 & -1.75 & $-8.06^{* * *}$ & $-8.04^{* * *}$ & $\mathrm{I}(1)$ \\
\hline & NAM & -2.39 & -2.41 & $-12.02^{* * *}$ & $-12.12^{* * *}$ & $\mathrm{I}(1)$ \\
\hline & $\mathrm{RSA}$ & -2.44 & $-3.45^{* *}$ & $-10.41^{* * *}$ & $-10.45^{* * *}$ & $\mathrm{I}(1)$ \\
\hline \multirow{4}{*}{ LGDP } & ESW & -1.64 & $-3.44^{* *}$ & $-11.91^{* * *}$ & $12.05^{* * *}$ & $\mathrm{I}(1)$ \\
\hline & LES & -2.37 & 1.84 & $-7.19^{* * *}$ & $-7.69^{* * *}$ & $\mathrm{I}(1)$ \\
\hline & NAM & -1.21 & -2.75 & $-13.51^{* * *}$ & $-13.57^{* * *}$ & $\mathrm{I}(1)$ \\
\hline & $\mathrm{RSA}$ & $-3.61^{* * *}$ & -1.27 & $-8.68^{* * *}$ & $-9.47^{* * *}$ & $\mathrm{I}(1)$ \\
\hline SARR & RSA & -1.99 & -2.31 & $-4.39^{* * *}$ & $4.40^{* * *}$ & $\mathrm{I}(1)$ \\
\hline
\end{tabular}

Note: The Augmented Dickey-Fuller (ADF) test is performed with the null hypothesis that the series has a unit root. The results present the value of the test-statistic, where $\left({ }^{*}\right) \rightarrow p<0.1,\left({ }^{* *}\right) \rightarrow p<0.05$, and $\left({ }^{* * *}\right) \rightarrow p<0.01$. 
Panel II: KPSS test results by country, 2000M2-2018M12

\begin{tabular}{|c|c|c|c|c|c|c|}
\hline & \multirow{2}{*}{ Country } & \multicolumn{2}{|c|}{ Levels } & \multicolumn{2}{|c|}{ First Differences } & \multirow{2}{*}{ Decision } \\
\hline & & Constant & Trend & Constant & Trend & \\
\hline \multirow{4}{*}{ LM1 } & ESW & 4.6385 & 0.5356 & $0.0683^{*}$ & $0.0586^{*}$ & $\mathrm{I}(1)$ \\
\hline & LES & 3.9946 & 0.5260 & $0.1322^{*}$ & $0.0510^{*}$ & $\mathrm{I}(1)$ \\
\hline & NAM & 3.4720 & 0.2511 & $0.0424^{*}$ & $0.0478^{*}$ & $\mathrm{I}(1)$ \\
\hline & $\mathrm{RSA}$ & 4.5826 & 0.7700 & $0.2680^{*}$ & $0.0667^{*}$ & $\mathrm{I}(1)$ \\
\hline \multirow{4}{*}{ LCPI } & ESW & 4.6619 & 0.2666 & $0.1587^{*}$ & $0.0417^{*}$ & $\mathrm{I}(1)$ \\
\hline & LES & 4.6517 & 0.6915 & $0.4576^{*}$ & $0.0534^{*}$ & $\mathrm{I}(1)$ \\
\hline & NAM & 4.5893 & 0.4007 & 1.0431 & $0.1412^{*}$ & $\mathrm{I}(1)$ \\
\hline & $\mathrm{RSA}$ & 4.6400 & 0.4278 & $0.0873^{*}$ & $0.0591^{*}$ & $\mathrm{I}(1)$ \\
\hline \multirow{4}{*}{$\mathrm{LDC}$} & ESW & $0.2225^{*}$ & 0.2089 & $0.0285^{*}$ & $0.0254^{*}$ & $\mathrm{I}(1)$ \\
\hline & LES & 3.9930 & 0.5673 & $0.0221^{*}$ & $0.06578^{*}$ & $\mathrm{I}(1)$ \\
\hline & NAM & 4.4341 & 1.0585 & 1.0977 & $0.0887^{*}$ & $\mathrm{I}(1)$ \\
\hline & RSA & 4.5194 & 1.0314 & 0.6532 & $0.0822^{*}$ & $\mathrm{I}(1)$ \\
\hline \multirow{4}{*}{ LRS } & ESW & 0.8715 & 0.8574 & $0.3334^{*}$ & $0.0819^{*}$ & $\mathrm{I}(1)$ \\
\hline & LES & 1.2771 & 0.8452 & $0.1151^{*}$ & $0.0796^{*}$ & $\mathrm{I}(1)$ \\
\hline & NAM & 2.7994 & 0.5297 & $0.0713^{*}$ & $0.0385^{*}$ & $\mathrm{I}(1)$ \\
\hline & $\mathrm{RSA}$ & 3.7683 & 0.5409 & $0.0623^{*}$ & $0.0315^{*}$ & $\mathrm{I}(1)$ \\
\hline \multirow{4}{*}{ LGDP } & ESW & 4.6568 & 0.2931 & $0.1459^{*}$ & $0.0329^{*}$ & $\mathrm{I}(1)$ \\
\hline & LES & 4.6670 & 0.4071 & $0.5871^{*}$ & $0.1682^{*}$ & $\mathrm{I}(1)$ \\
\hline & NAM & 4.6586 & 0.3016 & $0.0758^{*}$ & $0.0783^{*}$ & $\mathrm{I}(1)$ \\
\hline & $\mathrm{RSA}$ & 4.6133 & 1.0492 & 0.838 & $0.1072^{*}$ & $\mathrm{I}(1)$ \\
\hline SARR & RSA & 2.6999 & 0.2865 & $0.0928^{*}$ & $0.0411^{*}$ & $\mathrm{I}(1)$ \\
\hline
\end{tabular}

Note: The Kwiatkowski-Phillips- Schmidt-Shin (KPSS) test is performed with the null hypothesis that the series is stationary. KPSS use a Newey-West automatic bandwidth, using a Bartlett kernel. The results present the value of the test-statistic, where $\left(^{*}\right) \rightarrow p>0.05$. 


\section{C.4 Johansen Cointegration Test}

Panel I: Unrestricted Cointegration Rank Test (Trace)

\begin{tabular}{|c|c|c|c|c|c|}
\hline Country & $\begin{array}{l}\text { Hypothesized } \\
\text { No. of CE(s) }\end{array}$ & Eigenvalue & $\begin{array}{l}\text { Trace } \\
\text { statistic }\end{array}$ & $\begin{array}{l}5 \% \\
\text { vritical } \\
\text { alues }\end{array}$ & Prob. \\
\hline \multirow{6}{*}{ Eswatini } & None* & 0.1619 & 171.5018 & 95.7537 & 0.0000 \\
\hline & At most $1^{*}$ & 0.1156 & 109.0992 & 69.8189 & 0.0040 \\
\hline & At most 2 & 0.0883 & 42.7146 & 47.8561 & 0.1397 \\
\hline & At most 3 & 0.0700 & 22.1117 & 29.7991 & 0.2923 \\
\hline & At most 4 & 0.0179 & 5.9241 & 15.4947 & 0.7045 \\
\hline & At most 5 & 0.0084 & 1.8850 & 3.8415 & 0.1698 \\
\hline \multirow{6}{*}{ Lesotho } & None* & 0.2258 & 132.1317 & 95.7536 & 0.0000 \\
\hline & At most $1^{*}$ & 0.1275 & 75.0588 & 69.8189 & 0.0018 \\
\hline & At most 2 & 0.0768 & 44.6472 & 47.8561 & 0.0970 \\
\hline & At most 3 & 0.0660 & 26.8258 & 29.7971 & 0.1060 \\
\hline & At most 4 & 0.0344 & 11.6054 & 15.4947 & 0.1769 \\
\hline & At most 5 & 0.0168 & 3.7923 & 3.8415 & 0.0515 \\
\hline \multirow{6}{*}{ Namibia } & None* & 0.2792 & 196.7564 & 95.7536 & 0.0000 \\
\hline & At most $1^{*}$ & 0.1957 & 123.7396 & 69.8189 & 0.0000 \\
\hline & At most $2^{*}$ & 0.1256 & 75.1742 & 47.8561 & 0.0000 \\
\hline & At most $3^{*}$ & 0.0983 & 45.2479 & 29.7971 & 0.0004 \\
\hline & At most $4^{*}$ & 0.0781 & 2.2888 & 15.4947 & 0.1769 \\
\hline & At most $5^{*}$ & 0.0185 & 4.1626 & 3.8415 & 0.0515 \\
\hline \multirow{6}{*}{ South Africa } & None* & 0.1896 & 150.7818 & 95.7537 & 0.0000 \\
\hline & At most $1^{*}$ & 0.1747 & 103.9009 & 69.8189 & 0.0000 \\
\hline & At most $2^{*}$ & 0.1297 & 61.0785 & 47.8561 & 0.0018 \\
\hline & At most $3^{*}$ & 0.0681 & 30.0960 & 29.7991 & 0.0462 \\
\hline & At most 4 & 0.0560 & 14.3711 & 15.4947 & 0.0733 \\
\hline & At most 5 & 0.0068 & 1.15283 & 3.8415 & 0.2164 \\
\hline
\end{tabular}

Note: Trace test indicates no cointegration at the 0.05 level. $\left(^{*}\right)$ denotes rejection of the hypothesis at the $5 \%$ significance level. 


\section{C.5 VAR Lag Order Selection Criteria}

(a) Eswatini

\begin{tabular}{rccc}
\hline \hline Lag & LogL & AIC & SC \\
\hline 0 & 1748.048 & -15.606 & -15.484 \\
1 & 1970.139 & -17.024 & $-15.924^{*}$ \\
2 & 2087.568 & -17.503 & -15.425 \\
3 & 2152.990 & -17.516 & -14.460 \\
4 & 2263.043 & $-17.929^{*}$ & -13.895 \\
\hline
\end{tabular}

(c) Namibia

\begin{tabular}{rccc}
\hline \hline Lag & LogL & AIC & SC \\
\hline 0 & 2219.416 & -20.196 & -20.072 \\
1 & 2457.356 & -21.784 & $-20.670^{*}$ \\
2 & 2576.654 & -22.289 & -20.184 \\
3 & 2678.586 & -22.635 & -19.540 \\
4 & 2754.285 & $-22.742^{*}$ & -18.657 \\
\hline
\end{tabular}

(b) Lesotho

\begin{tabular}{rccc}
\hline \hline Lag & LogL & AIC & SC \\
\hline 0 & 2131.188 & -19.664 & -19.540 \\
1 & 2347.783 & -20.783 & $-19.669^{*}$ \\
2 & 2419.126 & $-20.850^{*}$ & -18.746 \\
3 & 2470.333 & -20.734 & -17.639 \\
4 & 2533.271 & -20.724 & -16.638 \\
\hline
\end{tabular}

(d) South Africa

\begin{tabular}{rccc}
\hline \hline Lag & LogL & AIC & SC \\
\hline 0 & 3453.701 & -31.468 & -31.344 \\
1 & 3682.650 & -32.974 & $-31.860^{*}$ \\
2 & 3775.333 & -33.236 & -31.131 \\
3 & 3856.498 & -33.393 & -30.298 \\
4 & 3945.685 & $-33.623^{*}$ & -29.537 \\
\hline
\end{tabular}

${ }^{*}$ Indicates the selected lag order by the criterion. AIC: Akaike information criterion,

SC: Schwarz information criterion

\section{C.6 Variance Decomposition Results}

Figure 1: Eswatini's Forecast Error Variance Decompositions
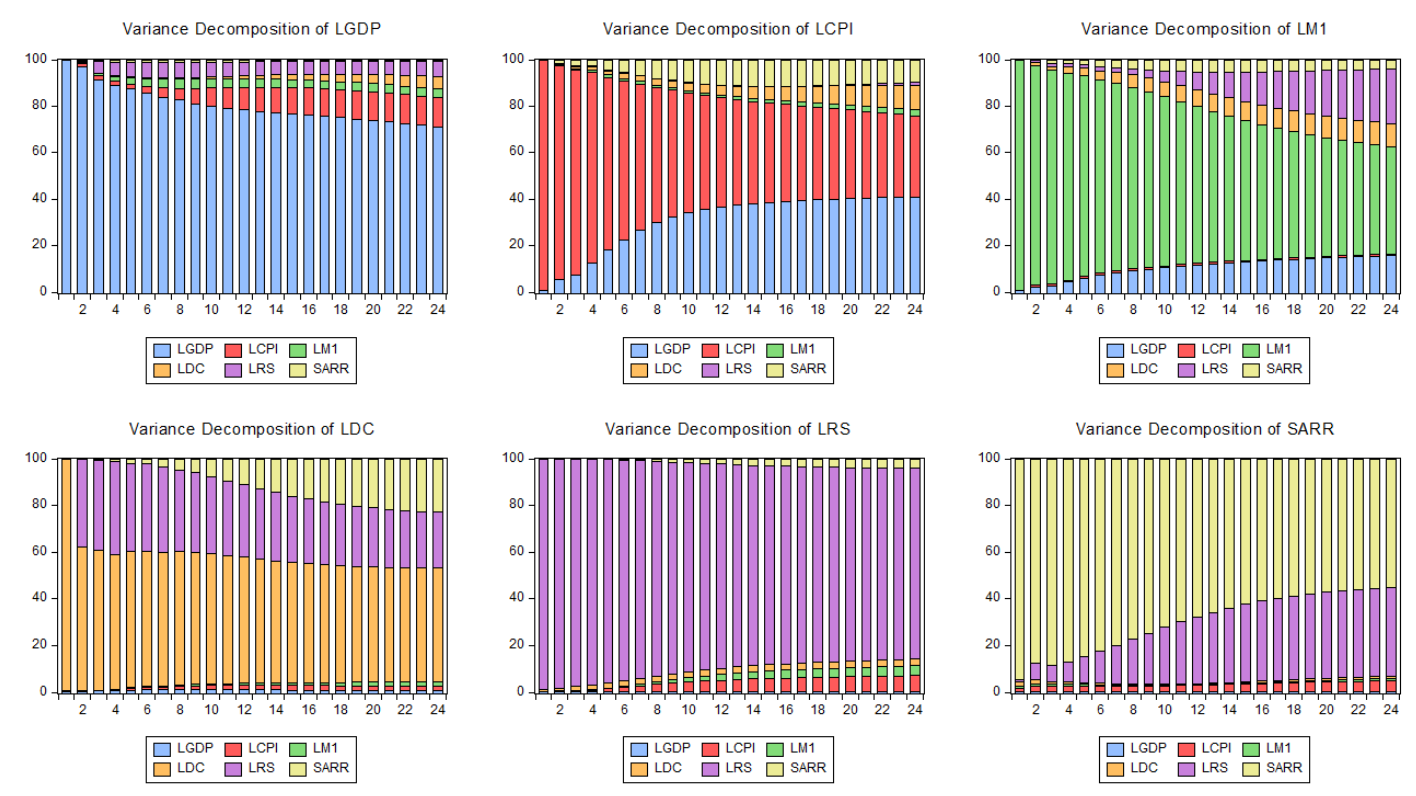
Figure 2: Lesotho's Forecast Error Variance Decompositions

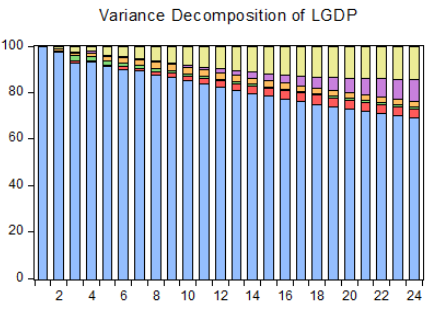

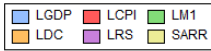

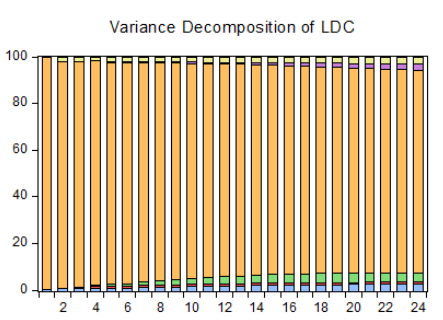

\begin{tabular}{|l|l|}
\hline LODP & LCPI \\
\hline LOC & LRS \\
\hline
\end{tabular}

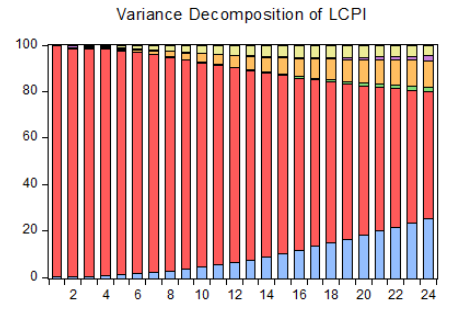

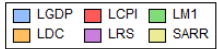

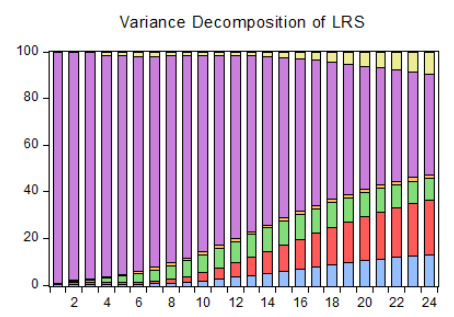

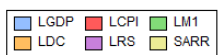

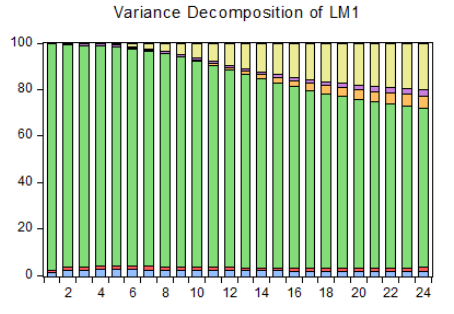

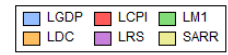

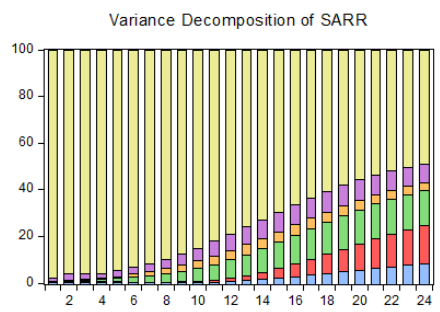

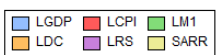

Figure 3: Namibia's Forecast Error Variance Decompositions

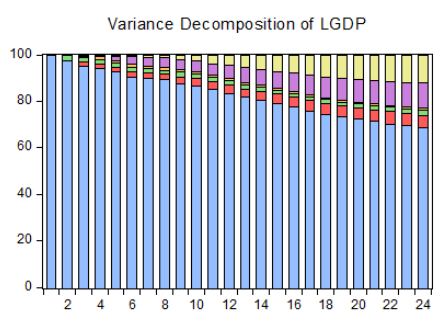

\begin{tabular}{l}
$Q^{\text {LGDP }} \square^{\text {LCPI }} \square^{\text {LM1 }}$ \\
\hline LRS \\
\hline SARR
\end{tabular}

Variance Decomposition of LDC

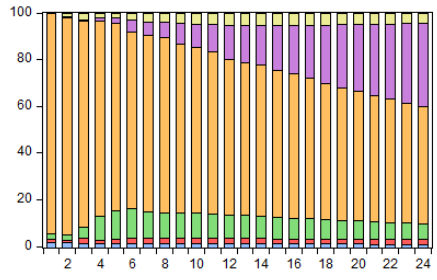

$\square^{\text {LGDP }} \square^{\text {LCPI }} \square_{\text {LDC }}^{\text {LM1 }}$
LRS
${ }_{\text {SARR }}$
Variance Decomposition of LCPI

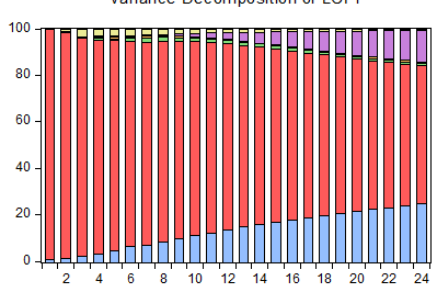

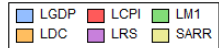

Variance Decomposition of LRS

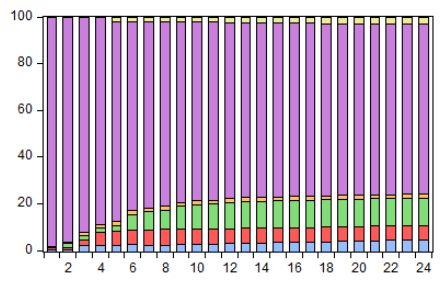

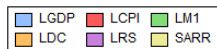

Variance Decomposition of LM1

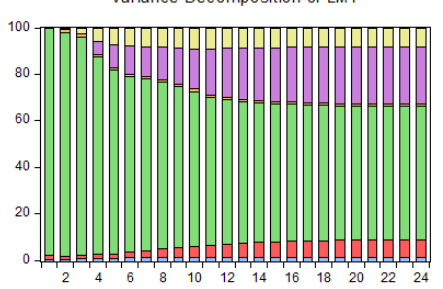

$\square$ LGDP $\square$ LCPI $\square$ LM1
$\square$ LDC $\square$ LRS $\square$ SARR

Variance Decomposition of SARR

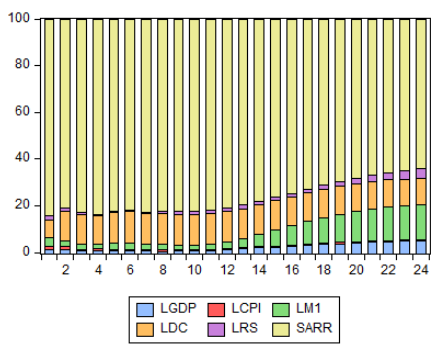


Figure 4: South Africa's Forecast Error Variance Decompositions
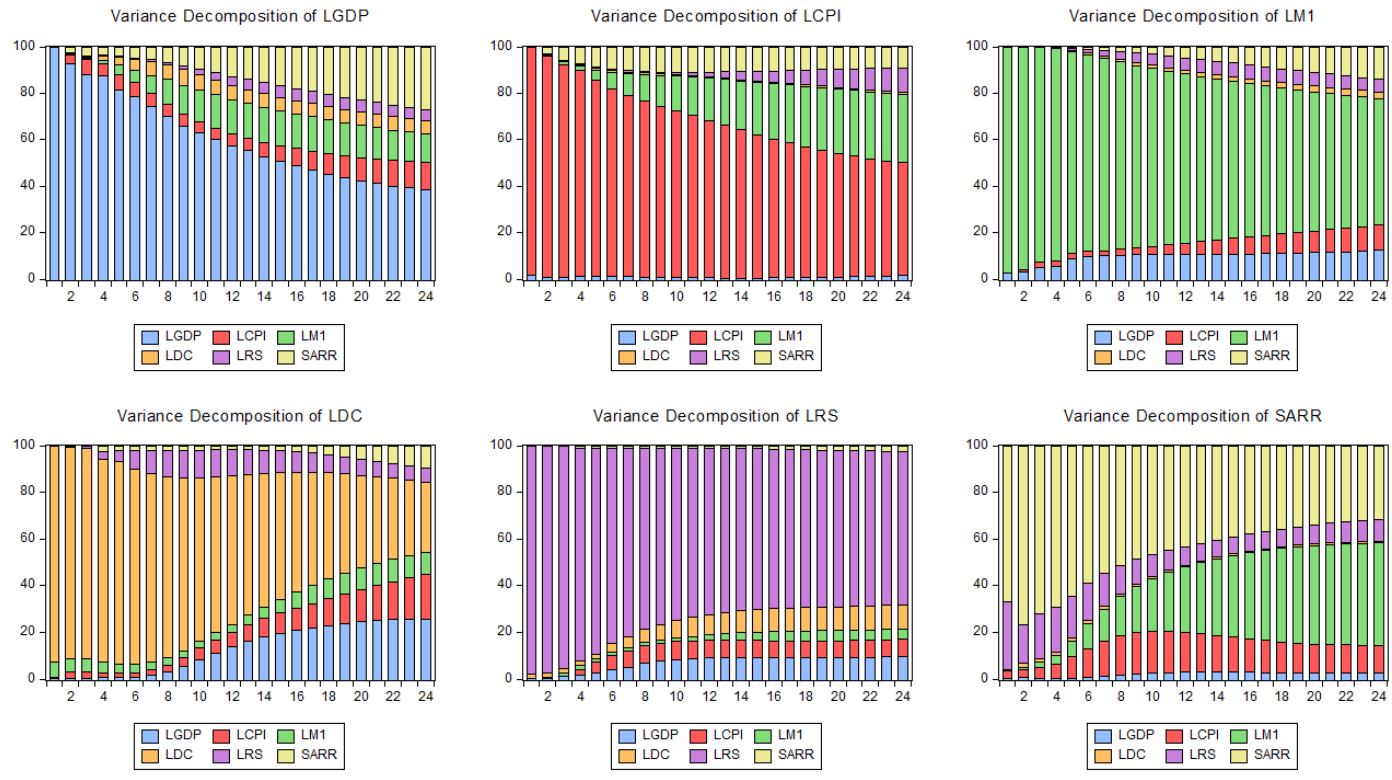

\section{C.7 Robustness Checks}

Figure 5: Impulse Response Functions to Repo Rate Shock

(a) Eswatini

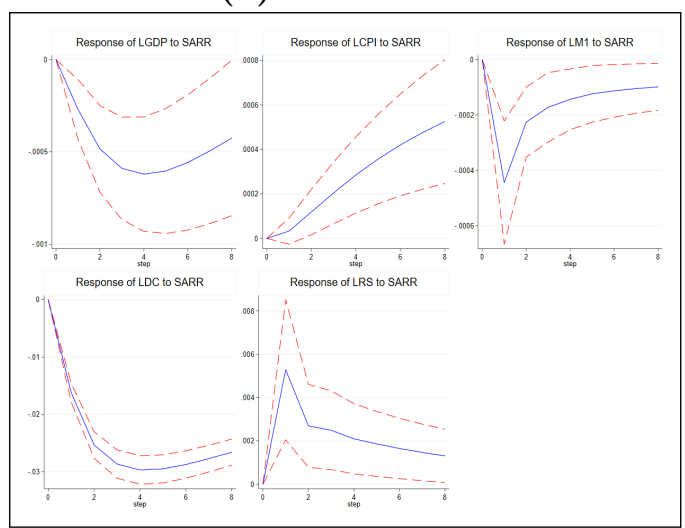

(c) Namibia

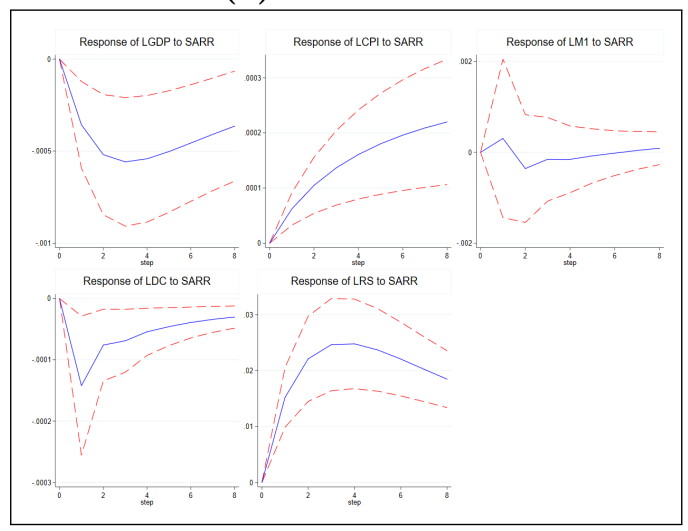

(b) Lesotho

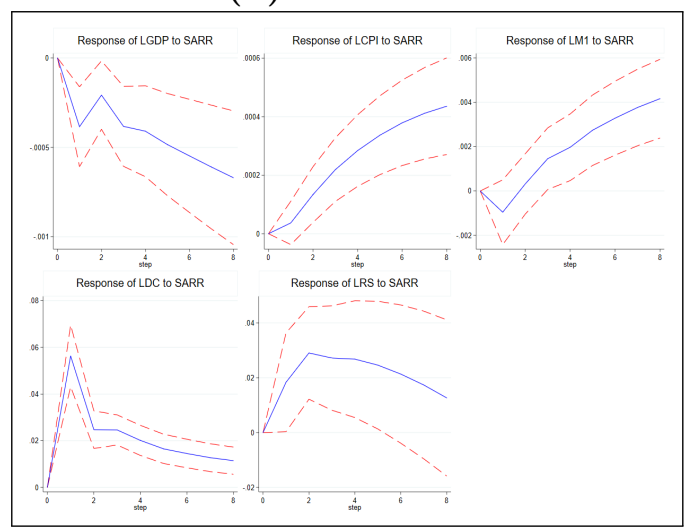

(d) South Africa

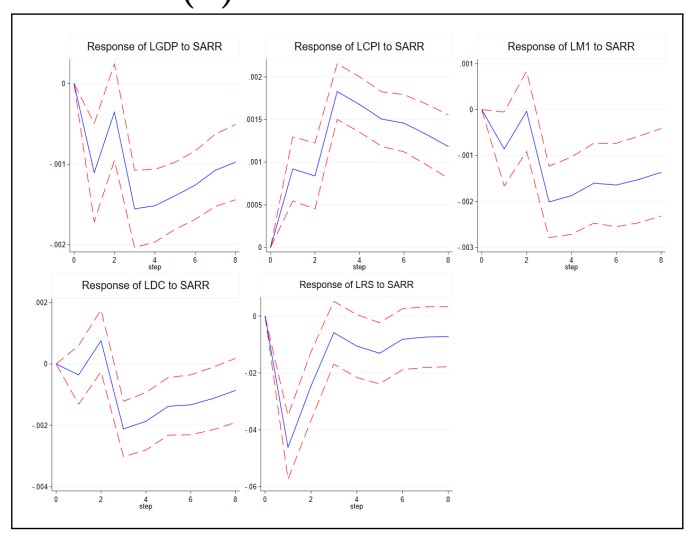


Panel III: Break Point Tests

(a) Eswatini

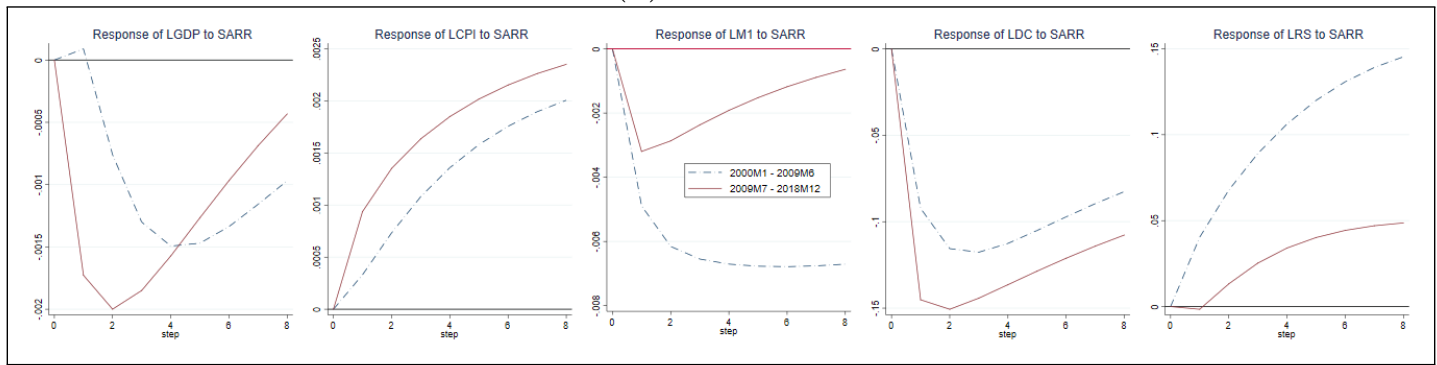

(b) Lesotho

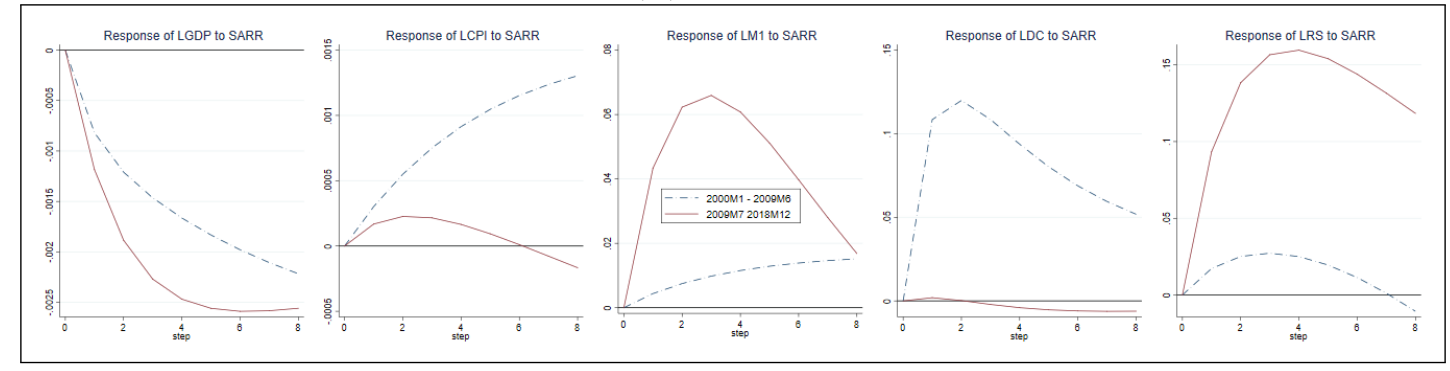

(c) Namibia

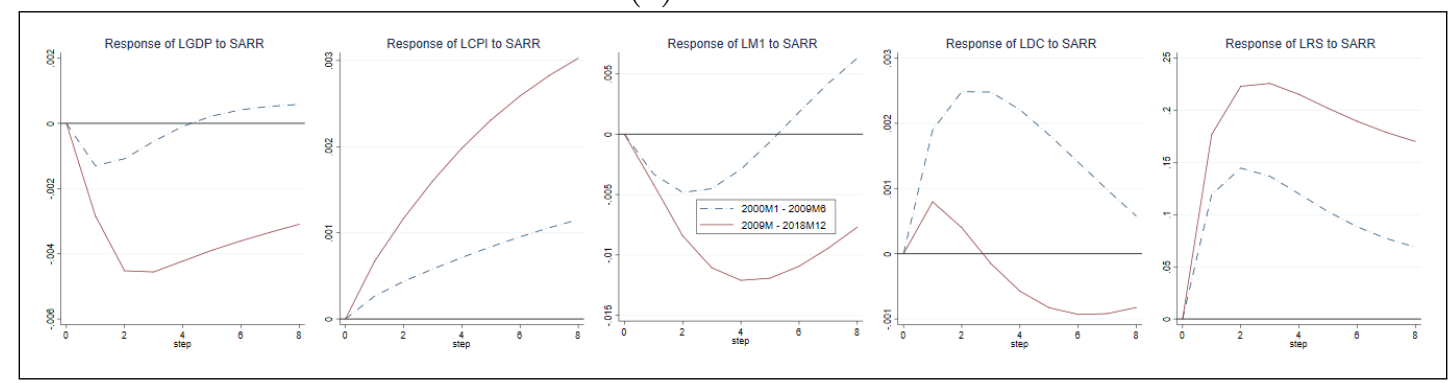

(b) South Africa

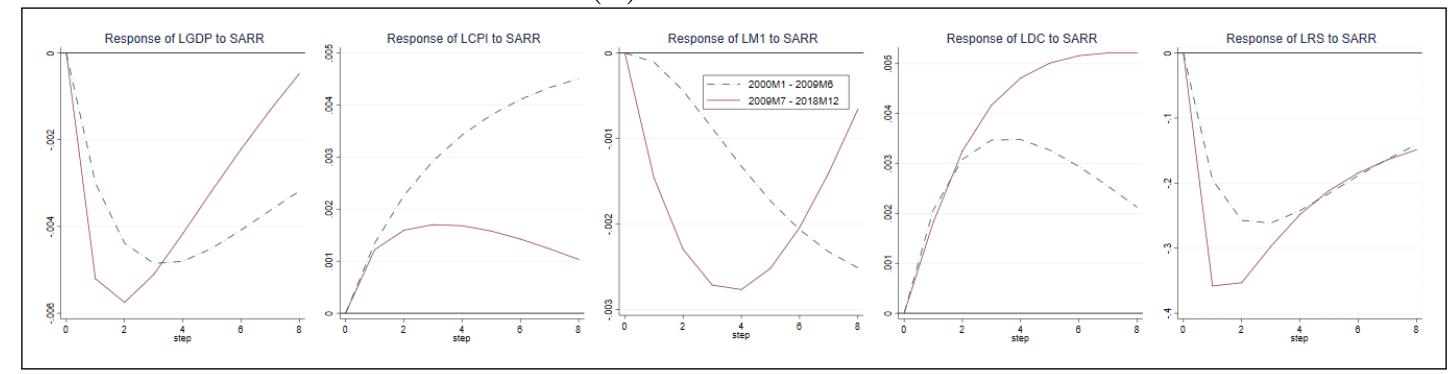

